\title{
Human milk microbiota associated with early colonization of the neonatal gut in Mexican newborns
}

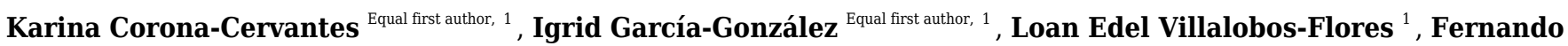 \\ Hernández-Quiroz ${ }^{1}$, Alberto Piña-Escobedo ${ }^{1}$, Carlos Hoyo-Vadillo ${ }^{2}$, Martín Noé Rangel-Calvillo ${ }^{3}$, Jaime García- \\ Mena ${ }^{\text {Corresp. } 1}$ \\ ${ }^{1}$ Departamento de Genética y Biología Molecular, Centro de Investigación y de Estudios Avanzados del Instituto Politécnico Nacional, Mexico City, CDMX, \\ Mexico \\ 2 Departamento de Farmacología, Centro de Investigación y de Estudios Avanzados del Instituto Politécnico Nacional, Mexico City, CDMX, Mexico \\ 3 Hospital General “Dr. José María Rodríguez”, Instituto de Salud del Estado de México, Ecatepec de Morelos, Estado de Mexico, Mexico \\ Corresponding Author: Jaime García-Mena \\ Email address: jgmena@cinvestav.mx
}

Background. Human milk microbiota plays a role in the bacterial colonization of the neonatal gut, which has important consequences in the health and development of the newborn. However, there are few studies about the vertical transfer of bacteria from mother to infant in Latin American populations. Methods. We performed a cross-sectional study characterizing the bacterial diversity of 67 human milk-neonatal stool pairs by highthroughput sequencing of V3-16S rDNA libraries, to assess the effect of the human milk microbiota on the bacterial composition of the neonate's gut at early days. Results. Human milk showed higher microbial diversity as compared to the neonatal stool. Members of the Staphylococcaceae and Sphingomonadaceae families were more prevalent in human milk, whereas the Pseudomonadaceae family, Clostridium and Bifidobacterium genera were in the neonatal stool. The delivery mode showed association with the neonatal gut microbiota diversity, but not with the human milk microbiota diversity; for instance, neonates born by C-section showed greater richness and diversity in stool microbiota than those born vaginally. We found 25 bacterial taxa shared by both ecosystems and $67.7 \%$ of bacteria found in neonate stool were predicted to originate from human milk. This study contributes to the knowledge of human milk and neonatal stool microbiota in healthy Mexican population and supports the idea of vertical mother-neonate transmission through exclusive breastfeeding. 


\section{Human milk microbiota associated with early}

\section{2 colonization of the neonatal gut in Mexican newborns.}

3 Karina Corona-Cervantes ${ }^{1} \uparrow$, Igrid García-González ${ }^{1} \uparrow$, Loan Edel Villalobos-Flores ${ }^{1}$, Fernando

4 Hernández-Quiroz ${ }^{1}$, Alberto Piña-Escobedo ${ }^{1}$, Carlos Hoyo-Vadillo ${ }^{2}$, Martín Noé Rangel-Calvillo ${ }^{3}$

5 and Jaime García-Mena ${ }^{1}$.

$6{ }^{1}$ Departamento de Genética y Biología Molecular, Centro de Investigación y de Estudios

7 Avanzados del Instituto Politécnico Nacional (Cinvestav), Ciudad de México, México.

8 2Departamento de Farmacología, Centro de Investigación y de Estudios Avanzados del Instituto

9 Politécnico Nacional (Cinvestav), Ciudad de México, México.

$10{ }^{3}$ Hospital General “Dr. José María Rodríguez”, Ecatepec de Morelos, Estado de México, México.

$11 \uparrow$ These two authors contributed equally.

Corresponding Author:

14 Jaime García-Mena ${ }^{1}$

15 Av. Instituto Politécnico Nacional 2508, Ciudad de México, GAM, 07360, México.

16 jgmena@cinvestav.mx

\section{Introduction}

Human milk provides essential nutrients, bioactive substrates (Fernández et al., 2013), as well as

\section{Abstract}

Background. Human milk microbiota plays a role in the bacterial colonization of the neonatal gut, which has important consequences in the health and development of the newborn. However, there are few studies about the vertical transfer of bacteria from mother to infant in Latin American populations. Methods. We performed a cross-sectional study characterizing the bacterial diversity of 67 human milk-neonatal stool pairs by high-throughput sequencing of V3$16 \mathrm{~S}$ rDNA libraries, to assess the effect of the human milk microbiota on the bacterial composition of the neonate's gut at early days. Results. Human milk showed higher microbial diversity as compared to the neonatal stool. Members of the Staphylococcaceae and Sphingomonadaceae families were more prevalent in human milk, whereas the Pseudomonadaceae family, Clostridium and Bifidobacterium genera were in the neonatal stool. The delivery mode showed association with the neonatal gut microbiota diversity, but not with the human milk microbiota diversity; for instance, neonates born by C-section showed greater richness and diversity in stool microbiota than those born vaginally. We found 25 bacterial taxa shared by both ecosystems and $67.7 \%$ of bacteria found in neonate stool were predicted to originate from human milk. This study contributes to the knowledge of human milk and neonatal stool microbiota in healthy Mexican population and supports the idea of vertical mother-neonate transmission through exclusive breastfeeding. prebiotics like the human milk oligosaccharides (HMOs) (Ward et al., 2006), required for growth 
40

41

42

43

44

45

46

47

48

49

50

51

52

53

54

55

56

57

58

59

60

61

62

63

64

65

66

67

68

69

70

71

72

73

74

75

76

77

78

79

80

and development of the newborn and infant at least during the first six months of life. The human milk also contains a rich community of bacteria that has been proposed to originate from the neonate's oral cavity, the breast surface (mother's skin), the lobules and lactiferous ducts in the lactating women (commonly called "Breastfeeding-Associated Microbiota"), or through an entero-mammary pathway. This last hypothesis states that maternal gut bacteria are translocated by dendritic cells through the intestinal epithelial barrier and are transported to the mammary glands via lymphatic circulation. From there, these bacteria colonize the gut of the breastfed neonate (Sakwinska et al., 2016; LaTuga et al., 2014; Fitzstevens et al., 2017; Donnet-Hughes et al., 2010; Fernández et al., 2013; Jost et al., 2014;). Most reported studies are of microbiota of milk collected applying sanitization procedures to the mammary gland, and only few have studied the bacteria communities of the entire breast milk collected without sanitization (Ward et al., 2013; Sakwinska et al., 2016).

The bacterial communities identified in the milk of healthy women are highly diverse and complex. Despite the great interindividual variability, several taxa have been identified as common constituents of milk microbiota, including Staphylococcuss spp., Streptococcuss spp., Pseudomonas spp., Propionibacterium sp., and Lactobacillus spp., as well as obligate anaerobic bacteria such as Bifidobacterium spp., Clostridium spp., and Bacteroides spp. (Hunt et al., 2011; Jost et al., 2014; Fitzstevens et al., 2017). These bacteria also represent the main groups involved in early gut colonization in healthy newborns (Nagpal et al., 2017).

Over the last few years, the vertical transmission of bacteria from the human milk to the infant gut has gained great interest as an important source or inoculum for bacterial colonization (Grönlund et al., 2007; Nagpal et al., 2017; Simpson et al., 2018). It is also proposed that gut microbiota acquisition begins in utero (Aagaard et al., 2014; Collado et al., 2016; Parnell et al., 2017; Stinson et al., 2019), being it another source of bacteria for the neonate. Likewise, although there is evidence of translocation of specific bacterial taxa from milk to the infant gut, the proportion of microbiota from the human milk that contributes to the colonization during the first days after birth has not been extensively characterized (Pannaraj et al., 2017).

The human milk microbial composition is influenced by factors that impact the early development of the gastrointestinal microbiota in the neonate, which include mode of delivery, diet, lifestyle, and geographical area where the mother lived during pregnancy (Khodayar-Pardo et al., 2014; Cabrera-Rubio et al., 2016; Kumar et al., 2016; Mueller et al., 2017). In Mexico, there are no published studies examining the bacterial ecosystems of milk and/or neonate gut in a cohort. Most research done to date, has focused on Spanish (Gomez-Gallego et al., 2016), Irish (Murphy et al., 2017), Canadian (Moossavi et al., 2019), western Italian (Biagi et al., 2017), and United States Caucasian populations (Hunt et al., 2011), whose ethnicities, lifestyles and environment exposures differ from the Mexican population. We believe that in the Mexican population the neonate's intestinal microbiota diversity is determined mostly by the microbiota found in the milk of its mother, and the delivery mode. In this context, the aim of this cross- 
81

82

83

84

85

86

87

88

89

90

91

92

93

94

95

96

97

98

99

100

101

102

103

104

105

106

107

108

109

110

111

112

113

114

115

116

117

118

119

120

sectional and comparative study was to evaluate the association of the human milk bacteria and the delivery mode with the neonate gut bacterial composition in a cohort of Mexican population based on the sharing of milk/ neonate gut bacteria. We also describe the predicted metabolic pathways in these bacterial communities.

\section{Materials \& Methods}

\section{Study design and selection of subjects.}

This descriptive cross-sectional study included 67 mother-neonate pairs recruited at General Hospital "Dr. José María Rodríguez", located in Ecatepec-de-Morelos, State of Mexico (19³6'35" N, 9903'36" W), between November 2017 and January 2018. Donors were healthy lactating women, and their healthy, full-term exclusively breastfed neonates. Milk and stool samples were collected from each mother-neonate pair between 1-6 days postpartum. Inclusion criteria to select the pairs were: (1) Mexican origin for at least two generations, (2) gestational age between 37 and 41 weeks, (3) spontaneous vaginal delivery or non-elective C-section, (4) birth weight greater than 2,500 g and less than 4,500 g, and (5) Apgar score greater than 7 at 5 minutes after birth. Exclusion criteria: (6) probiotics and alcohol consumption, (7) smoking, (8) diabetes, overweight and obesity before or during pregnancy, and (9) antibiotics use during the last trimester of pregnancy and prior to sample collection. Based on a questionnaire, sociodemographic and clinical information were recorded (maternal age, gestational age at delivery, delivery mode, sex and age of newborn). Informed consent was obtained from all donors before starting the study in accordance with the Declaration of Helsinki 2013. The protocol was approved by the Ethics Committee of the General Hospital "Dr. José María Rodríguez" (Project identification code: 217B560002018006).

\section{Sample collection.}

All samples were obtained by one member of the research team wearing sterile gloves. Each milk-neonatal stool sample pair was collected the same day in the morning up to 2 hours after the neonate was breastfed. Milk for the study was manually collected $(5-10 \mathrm{~mL})$ into a sterile polypropylene tube without breast sanitization to give a more representative analysis of the bacteria ingested by the suckling neonate. At the same time, fecal samples were taken after 20 minutes at most, directly from diapers into sterile containers with the help of sterile tongue depressors. All samples were immediately transported to the laboratory using cold packs and dispensed in aliquots of $1 \mathrm{~mL}$ of milk or $200 \mathrm{mg}$ of stool and stored at $-20^{\circ} \mathrm{C}$ until processing for DNA extraction within 24 hours of receipt.

\section{DNA extraction.}

Prior to DNA extraction, $1 \mathrm{~mL}$ of milk was centrifuged at $10,000 \mathrm{~g}, 15$ minutes at $4^{\circ} \mathrm{C}$ in a refrigerated centrifuge (Eppendorf 5415R) and fat was removed using a sterile dental cotton roll. Aqueous supernatant was removed by decantation, the pellet resuspended in $1.0 \mathrm{~mL}$ sterile PBS 
$121 \mathrm{pH} 7.4$, then recentrifuged at $10,000 \mathrm{~g}$ for 15 minutes. The obtained pellet was resuspended in $122300 \mu \mathrm{L}$ of PBS pH 7.4 and processed for DNA extraction using FavorPrep Milk Bacterial DNA 123 Extraction Kit (Cat.: FAMBD001, Favorgen, Biotech Corp, Taiwan) following the 124 manufacturer's instructions. Fecal DNA was extracted from $200 \mathrm{mg}$ stool samples using a 125 QIAamp DNA Stool Mini Kit (Cat.: 12830-50, Qiagen, Netherlands), following the

126

127

128

129

130

131

132

133

134

135

136

137

138

139

140

141

142

143

144

145

146

147

148

149

150

151

152

153

154

155

156

157

158

159

160 manufacturer's instructions. In both cases $300 \mu \mathrm{L}$ of PBS pH 7.4 was used as negative control for DNA extraction. The DNA concentration in samples was measured at 260/280 absorbance using a Nano Drop 2000 spectrophotometer (Thermo Scientific, USA), no absorbance was detected for the negative controls. The DNA integrity was evaluated by electrophoretic fractionation in $0.5 \%$ agarose gel. DNA was stored at $-20{ }^{\circ} \mathrm{C}$ until library preparation and sequencing.

\section{Preparation of the 16S rDNA library and high-throughput sequencing.}

For each DNA sample, a $\sim 281 \mathrm{bp}$ amplicon containing the V3 hypervariable region of the $16 \mathrm{~S}$ RNA gene was amplified using V3-341F forward primer (set of barcodes 1-100) complementary to positions 340-356 of the Escherichia coli 16S rDNA molecule rrnB GenBank J01859.1, and the V3-518R reverse primer complementary to positions 517-533 of same molecule (Fierer et al., 2008; Murugesan et al., 2015) (Table S1). All PCR reactions were performed in a final volume of $25 \mu \mathrm{L} 1 \mathrm{X}$ SYBR Green PCR Master Mix (Bio-Rad Laboratories Cat\# 1725270), 0.3 $\mu \mathrm{M}$ of each primer, and 10-25 ng of each DNA template. The PCR conditions were as previously reported with exception that 30-cycles were used (Murugesan et al., 2015). The 281 bp amplicon was not observed for the negative controls thus they were not sequenced. For library preparation equal mass amounts of each 1-100 barcoded amplicons were quantified by gel densitometry and pooled. The mixture was purified using E-Gel iBase Power System (Invitrogen). The libraries size and concentration were confirmed using the Agilent 2100 Bioanalyzer system and High Sensitivity DNA Kit (Agilent, USA). High-throughput sequencing was performed using Ion OneTouch 2, Ion PGM Template OT2 200 Kit v2 DL (Life Technologies, California, USA), Ion 318 Chip Kit v2 and Ion Torrent PGM System as previously described (Chávez-Carvajal et al., 2019). After sequencing, reads were filtered by the PGM software to exclude low quality and polyclonal sequences. The quality control of sequences was performed using FastQC

(https://www.bioinformatics.babraham.ac.uk/projects/fastqc/), and all reads were trimmed to 200 nt length using Trimmomatic v0.36. Filtered and demultiplexed FASTQ files were converted into FASTA files, concatenated into a single file and then processed with multiple QIIME (Quantitative Insights into Microbial Ecology) v1.9.0 scripts (Caporaso et al., 2010). DNA sequences were classified into Operational Taxonomic Units (OTUs) using closed based picking parameters with a $97 \%$ similarity level against Greengenes database v13.8. The sequence and corresponding mapping files for all samples used in this study were deposited in the NCBI BioSample repository (Accession Number: PRJNA548324) link: https://www.ncbi.nlm.nih.gov/bioproject/?term=PRJNA548324 
161

162

163

164

165

166

167

168

169

170

171

172

173

174

175

176

177

178

179

180

181

182

183

184

185

186

187

188

189

190

191

192

193

194

195

196

197

198

199

\section{Microbial abundance and diversity analyses.}

The relative abundance of bacterial communities at phylum and family taxonomic levels was determined for human milk or neonatal stool samples using QIIME pipeline v1.9.0. The linear discriminant analysis effect size program (LEfSe v1.0) was used to detect significant differences in the relative abundances of bacterial taxa among milk and stool samples, and vaginal and $\mathrm{C}$ section delivery mode samples. We used the LDA (linear discriminant analysis) to estimate the effect size of each taxa between groups with LDA-scores $\geq 2.5$ (Segata et al., 2011). To characterize the microbial diversity patterns, we calculated alpha and beta diversities. Prior to calculate alpha diversity, the OTU table was rarefied at 10,000 sequences per sample (samples with $<10,000$ were omitted) using a "single_rarefaction.py" QIIME script for the four alpha diversity metrics: observed species (number of unique OTUs), Chaol index (bacterial richness estimator), and the community diversity Simpson (dominance) and Shannon (evenness) indexes were determined using phyloseq and ggplot2 packages in R environment (v3.4.4). The Effectsize was measured using the Hedges' $g$ statistic and calculated with STATA SE 10.1 software. For beta diversity, the dissimilarity was estimated using weighted and unweighted UniFrac analyses. A two-dimensional scatter plot was generated using principal coordinate analysis (PCoA) with QIIME.

\section{Shared OTUs, core microbiota and microbial source tracking analysis.}

To determine the number of OTUs in the microbial community shared between the human milk and the neonatal stool samples the shared_phylotypes.py QIIME script was run, then a Venn Diagram was generated using the Bioinformatics and Evolutionary Genomics web tool (Shade \& Handelsman, 2012). Next, we used the compute_core_microbiome.py QIIME script to identify which taxa are shared in at least $50 \%$ of mother-neonate pairs, and a heatmap of counts was made in R environment (gplots and RColorBrewer packages). We performed Source Tracker analysis to predict the origin of OTUs in each neonatal stool sample using the corresponding human milk as potential source, to estimate the proportion of bacteria present in the neonatal stool attributable to the human milk. This analysis was made in QIIME platform using Source Tracker (v0.9.5) software (Knights et al., 2011). A file with the mean of all these data was used to show the proportion of OTUs present in the neonatal stools corresponding to "human milk" or "unknown source" which indicate other possible sources not evaluated. Data were visualized as pie chart plots for each sample and for total samples.

\section{Metagenome prediction with PICRUSt.}

We used Phylogenetics Investigation of Communities by Reconstruction of Unobserved States (PICRUSt, v1.1.1) (Langille et al., 2013) to predict the metabolic function of the metagenomes from 16S rRNA gene data set, with Kyoto Encyclopedia of Genes and Genomes (KEGG) orthologs classification database at hierarchy level 3 pathways. Statistical Analysis of 
200 Taxonomic and Function software (STAMP v2.1.3) was used to determine significant

201 differences in abundance of OTUs and metabolic pathways.

202

203 Statistical methods.

204 The epidemiological data were reported as mean \pm standard deviation (SD), or frequencies and

205 percentages. Two-tailed student's t-test, Mann-Whitney U, or Wilcoxon signed-rank

206 nonparametric test were assessed to compare groups using SPSS v23.0 software (SPSS, Inc).

207 ANOSIM and Adonis were used for category comparisons of phylogenetic distance matrices

208 (UniFrac). Linear regression was used to know the relationship between microbiota diversity as

209 the dependent variable and maternal and neonatal age included as covariates; $\mathrm{p}<0.05$ was

210 considered statistically significant. The Benjamini-Hochberg $(\mathrm{BH})$ correction method was used

211 to estimate the false discovery rate (FDR) and filter the data where a q-value $<0.05$ was

212 considered statistically significant.

213

214

Results

215

216

217

Participating women were from a poor urban polluted area.

218

219

220

We characterized the human milk microbiota of 67 lactating relatively healthy Mexican women aged 14 to 41 years-old, and the gut microbiota present in the stool of their respective neonates aged $<6$ days-old, fed exclusively with breast milk. In this cohort, most women were

221 housewives living in "Ecatepec-de-Morelos" (19 29'4.56"N, 99 $\left.9^{\circ} 6.96^{\prime \prime} \mathrm{W}\right)$, an overcrowded

222 municipality area $\left(8,860\right.$ inhabitants $\left./ \mathrm{km}^{2}\right)$ of the "Estado-de-México" a state located in the central part of Mexico (https://www.inegi.org.mx/app/areasgeograficas/default.aspx). At 2,248

223 meters over sea level, "Ecatepec-de-Morelos" has a subtropical highland climate (Köppen:

224

225 $\mathrm{Cwb}$ ), and $75.2 \%$ of the population lives in a situation of moderate to extreme poverty (https://www.coneval.org.mx/Medicion/Paginas/Pobreza-municipal.aspx). Participating women

226

227 had mostly a high school or college educational level. With respect of neonates, most of them were females born by vaginal delivery (Table 1).

228

229

\section{Proteobacteria was the most abundant phylum in the mother-neonate pair.}

230

231

We characterized the bacterial diversity in the human milk and stool samples collected from the

232 mother-neonate pairs by high-throughput DNA semiconductor sequencing of V3-16S rDNA

233 libraries. In general, we obtained 9,575,537 raw sequence reads with a mean length of $169.3 \mathrm{bp}$

234 $( \pm 46.1)$ for the total of 134 samples analyzed; 4,240,314 for human milk and 5,335,223 for

235

236 neonatal stool with a phred33 average value of 31 . A mean length 170 bases were selected for analyses (Table S2). The alpha rarefaction curves show that the deep of sequencing among samples was sufficient to process the data (Fig. S1).

237

238 We found that Proteobacteria, Firmicutes, Actinobacteria, and Bacteroidetes accounted for 239 97.19\% of sequences in human milk (Fig 1A) and 98.03\% in neonatal stool (Fig 1B). The phylum Proteobacteria was more abundant in human milk $(55.40 \% \pm 32.1)$ than in neonatal stool 
$240(36.70 \% \pm 31.0)$ being this the only phylum with a statistical significance difference $(\mathrm{p}=0.001$, $241 \mathrm{q}=0.041)$. Although with no statistically significant difference, the relative abundance of 242 Firmicutes was larger in neonatal stool $(32.10 \% \pm 33.2)$ than human milk $(25.80 \% \pm 28.9)(\mathrm{p}=$ $2430.243, \mathrm{p}=1.00)$; the phylum Actinobacteria was more abundant in neonatal stool $(18.73 \% \pm$ 244 23.5) than human milk $(13.20 \% \pm 11.7)(\mathrm{p}=0.088, \mathrm{q}=1.00)$; while the relative abundance of 245 Bacteroidetes was higher in neonatal stool $(10.50 \% \pm 21.5)$ than in human milk $(2.79 \% \pm 9.9)(\mathrm{p}$ $246=0.009, \mathrm{q}=0.185)$. In addition, the phyla Acidobacteria, Cyanobacteria, Fusobacteria,

247 Chloroflexi and Armatimonadetes with less than $1 \%$ of relative abundance, were grouped as 248 "Others", and they accounted for $2.83 \%( \pm 1.12)$ in human milk and $1.94 \%( \pm 0.47)$ in neonatal 249 stool. These differences had no statistical significance $(\mathrm{p}=0.598, \mathrm{q}=1.00)$ (Fig 1A, 1B).

250

251

252

253

254

255

256

257

258

259

260

261

262

263

264

265

266

267

268

269

270

271

272

273

274

275

276

277

278

279

In addition to the phylum, we analyzed the bacterial composition at family level in both groups (Fig $1 \mathrm{C}$ and Table S3). We found 14 predominant families with a relative abundance $\geq 1 \%$ in at least $97 \%$ of samples. The relative abundance of Staphylococcaceae, Sphingomonadaceae, Rhodobacteraceae, Bradyrhizobiaceae, and Propionibacteriaceae was higher in human milk with respect to neonatal stool. In contrast, Pseudomonadaceae, Clostridiaceae, and Bifidobactericeae showed higher relative abundance in neonatal stool. On the other hand, Streptococcaceae, Weeksellaceae, and Lachnospiraceae were equally abundant in both groups. The relative abundance of some of these families showed higher inter-individual variation among members in each group (Table S3).

\section{There is a significant difference in the abundance of some bacterial taxa between human} milk and neonate stool.

We used LEfSe analysis to identify differences in the abundance of bacterial taxa between human milk and neonatal stool microbiota, using an LDA score cutoff of 3.5. Fourteen taxa were predominant in the human milk samples and six taxa in neonatal stools. Identified taxa in human milk included ten genera Staphylococcus, Kaistobacter, Paracoccus, Pseudomonas,

Bradyrhizobium, Methylobacterium, Acinetobacter, Propionibacterium, Corynebacterium, and Microbacterium; three families Phyllobacteriaceae, Sphingomonadaceae, Gemellaceae, and the order Streptophyta (average $\mathrm{p}=1.91 \mathrm{E}-5$ and $\mathrm{q}=1.07 \mathrm{E}-3$ ). Likewise, in the stool samples, we found members of three families Pseudomonadaceae, Clostridiaceae, and Enterobacteriaceae; and three genera Bifidobacterium, Clostridium, and Bacteroides (average $\mathrm{p}=4.26 \mathrm{E}-5$ and $\mathrm{q}=$ 9.67E-5) (Fig 2 and Table S4).

\section{The Human milk microbiota diversity was higher than the diversity in neonatal stool.}

We estimated the alpha diversity of the microbiota in human milk and neonatal stool samples and Mann-Whiney U test to find significant differences between both groups (Fig 3A - 3D and Table S5). To estimate microbial richness, we used the Chao1 index (Effect size 0.894, $\mathrm{p}<$ 0.001 ) and Observed number of species (Effect size 0.861, $\mathrm{p}<0.001$ ) which revealed a difference between both groups showing higher richness in milk microbiota. With respect to the 
280

281

282

283

284

285

286

287

288

289

290

291

292

293

294

295

296

297

298

299

300

301

302

303

304

305

306

307

308

309

310

311

312

313

314

315

316

317

318

319

diversity and dominance, the Shannon (Effect size 0.745, $\mathrm{p}<0.001$ ) and Simpson (Effect size $0.584, p=0.006$ ) indexes showed higher bacterial diversity in human milk samples compared to the neonatal stool microbiota. Only the Simpson index did not show significant difference after the FDR correction (Table S5). Next, the beta diversity based on unweighted UniFrac analysis revealed two clusters separating both groups of samples as is illustrated by the three $2 \mathrm{D}$ images of the analysis (ANOSIM, $\mathrm{R}=0.289, \mathrm{p}=0.001$ ) (Fig 3E $-3 \mathrm{G}$ ). To confirm these statistical differences between both bacterial communities Adonis test was calculated $\left(\mathrm{R}^{2}=0.949, \mathrm{p}=\right.$ 0.001) and Weighed UniFrac analysis was also performed (Fig S2).

\section{The delivery mode is associated with the neonatal gut microbiota but not the human milk} microbiota diversity.

We observed that the bacterial diversity and richness of the neonatal fecal microbiota are associated with the delivery mode, nevertheless a similar effect was not observed for the human milk microbiota (Table S6). The observed species (Effect size 0.071, p =0.003), Chao1 richness indexes (Effect size 0.067, $\mathrm{p}<0.006$ ) and Shannon diversity indexes (Effect size 0.086, $\mathrm{p}=$ 0.046) were significantly higher in stool samples from neonates delivered by $\mathrm{C}$-section compared to those born by vaginal delivery (Fig 4A - 4D and Table S6). Likewise, the beta diversity analysis revealed that the fecal microbiotas of $\mathrm{C}$-section delivered neonates were different to those born vaginally (ANOSIM: $\mathrm{R}=12.52, \mathrm{p}=0.006$; Adonis: $\mathrm{R} 2=0.0401, \mathrm{p}=0.001)$ (Fig S3).

We also used LEfSe analysis to identify bacteria with relative abundance, significantly different between groups. We found a significant larger number of taxa (thirteen genera and three families) in the stool of neonates born by C-section compared with those born by vaginal delivery (three genera, two families and one order). Among these, Staphylococcus was the most abundant genus in the neonates delivered by $\mathrm{C}$-section, and the family Pseudomonadaceae was the most abundant in neonates born by vaginal delivery (Fig S4). Finally, we evaluated the association of maternal and neonatal age on the bacterial diversity applying a lineal regression analysis. For the human milk the richness (Chao1) (Fig. S5A) and the diversity (Shannon) (Fig. S5B) have a slight tendency to decrease as the age of the mother increases; same indexes slightly increased with the days after delivery for the neonatal stool (Fig. S5E, S5F), and for the human milk, the richness does not have an apparent change (Fig. S5C) while the diversity has a tendency to increase with the days after delivery (Fig. S5D).

\section{Specific bacterial taxa are transferred from human milk to the neonatal gut from the first} day of life.

As a first approach to explore the transferring of bacteria from human milk to the neonatal gut, we focused our attention to OTUs shared between each homologous mother-neonate pair. In general, from the 11,930 observed OTUs only 4,755 (39.85\%) were shared. We found that 3,847 OTUs (32.24\%) from human milk were not found in the neonate stool, while 3,328 OTUs $(27.89 \%)$ from neonate stool were not found in the human milk (Fig 5A). Relevant shared taxa 
320 between human milk and neonatal stool were the families Pseudomonadaceae, Clostridiaceae, 321 Sphingomonadaceae, and Bradyrhizobiaceae, and the genera Clostridium gasigenes, Bacteroides 322 spp., Bifidobacterium spp., Staphylococcus spp., Enterococcus spp., Streptococcus spp., and 323 Propionibacterium acnes (Fig 5B and Table S7).

324 Next, we used microbial source tracking analysis to estimate the proportion of bacteria in the 325 neonatal stool which originated from the human milk (Fig. S6). Data showed that neonates

326

327

328

329

330

331

332

333

334

335

336

337

338

339

340

341

342

343

344

345

346

347

348

349

350

351

352

353

354

355

356

357

358

359 received $67.8 \%( \pm 36.5)$ of bacteria from human milk, while the remaining $32.2 \%( \pm 36.5)$ came from unknown sources ( $p<0.006$, Wilcoxon signed-rank test) (Fig 6A). The taxonomic analysis of the bacteria in the fecal samples identified as "Unknown Source Group" showed a high significant relative abundance of the orders Clostridiales followed by Bacteroidales, Lactobacillales, and Enterobacteriales, which was different to the abundance found in "Human Milk Group" (Fig 6B).

\section{The predicted functional metagenome shows greater carbohydrate metabolism in neonate} gut and greater lipid metabolism in human milk microbiotas.

We determined the functional metabolic pathways present in the human milk and neonatal stool microbiota by PICRUSt analysis using the OTU table. At level three of analysis (the most specific) 10 KEGG pathways out of 92 , showed statistically significant difference between human milk and neonate stool microbiotas (average $\mathrm{p}=3.80 \mathrm{E}-03$, average $\mathrm{q}=8.74 \mathrm{E}-03$ ) (Fig 7 and Table S8). The functional pathways were related to energy metabolism, bacterial colonization and immune function. The human milk showed a high abundance of bacterial metabolic pathways associated to fatty acid metabolism, whereas the fecal microbiota from neonates had a higher abundance of pathways involved in carbohydrate metabolism, vitamin B6 metabolism, bacterial colonization and immune function.

\section{Discussion}

Human milk provides all required nutrients for infant nourishment; in addition, it contains a community of bacteria transferred through breastfeeding that plays a fundamental role in the development of the infant gut microbiota. In this cross-sectional study, we characterized the profile of the human milk microbiota from healthy Mexican mothers and the fecal microbiota of their neonates, finding that human milk contributes with the $67.7 \%$ of the bacteria within the first six days postpartum. Previous studies have reported both similarities and differences when comparing bacterial profiles of paired samples (human milk/neonatal stool) in different populations (Table 2). In our work we found high levels of Proteobacteria (55.4\%) and Firmicutes $(25.8 \%)$, represented by members of the Pseudomonadaceae and Staphylococcaceae families, present in $71.6 \%$ and $82.1 \%$ of milk samples respectively (Table S3).

Pseudomonadaceae family, for example, has been reported in human milk with an abundance of up to $61 \%$ during the first 30-days postpartum in a Canadian population (Ward et al., 2013), and an abundance of $17 \%$ during the 6 weeks postpartum in an Irish population (Murphy et al.,2017), while the Staphylococcaceae family has been reported with an average abundance of $20 \%$ in 
360

361

362

363

364

365

366

367

368

369

370

371

372

373

374

375

376

377

378

379

380

381

382

383

384

385

386

387

388

389

390

391

392

393

394

395

396

397

398

399

several reports (Table 2). We believe that the presence of Staphylococcaceae is a common feature of human milk microbiota, regardless of the geographical location. Conversely, the Sphingomonadaceae, and Rhodobacteraceae families represented by the Kaistobacter and Paracoccus genera respectively, were abundant in human milk samples in our study, nevertheless, these two taxa have been poorly reported in other studies on human milk microbiota in healthy women (Table 2). To our knowledge, there is no available information about the possible functional role of these bacteria in breast milk on regard of the neonate gut, but the Sphingomonadaceae family, has been also detected in high abundance in nipple skin and nipple aspirate fluid samples in healthy women (Chan et al., 2016; Hieken et al., 2016). It is suggested this family contributes to the maintenance of healthy breast tissue and protects against breast cancer through stimulation of the host immune cells (Chan et al., 2016) (Table 3). A relevant finding was the low relative abundance in our milk samples of Bifidobacteriaceae ( $0.73 \%)$, Streptococcaceae (3.73\%) families and genus Lactobacillus $(0.21 \%)$; since these taxa have been reported in high abundance as part of a predominant "core microbiota" in human milk from healthy women in other studies (Fernández et al., 2013; Jiménez et al., 2015; Kumar et al., 2016). For example, in the CHAMACOS study performed in Mexican American women suffering of overweight and obesity (Davé et al., 2016), and in Peruvian healthy women (Lackey et al., 2019), Streptococcus was the dominant genus (73.8\% and $49.6 \%$ respectively), however in our study, this taxa barely reached a relative abundance of $2.3 \%$. We think that for human milk there is a "core microbiota" plus additional resident bacteria which are unique for each population, whose variability is influenced by the genetic composition, geographical area, lactation stage, diet, lifestyle, and environmental conditions that surrounds the mother.

The characterization of the neonate fecal microbiota showed less diversity than the human milk microbiota, as well as a high dominance of bacterial groups (Fig 3), which suggest that in the first six days of life, only few selected taxa contribute to the initial colonization of the gut microbiota. The high dominance of Pseudomonadaceae (24.5\%) in 77.6\% of neonate fecal samples, suggests a possible selection process occurred in the infant gut (Fig 5B). We think these bacteria come mostly from human milk and constitute an inoculum for the gut colonization at early age (Fig 6B). It has been already described the presence of Pseudomonas aeruginosa in the gut of healthy newborns during the first week of life without any manifestation of disease (Borderon et al., 1990). Although the presence of Pseudomonas spp. in several body niches have been documented in healthy subjects (Dekio et al., 2005; Urbaniak et al., 2014; Ozkan et al., 2019), a potential functional role remains undefined. We can speculate these bacteria are selected for its ability to migrate and bind to the mucosal barrier of the epithelial cells (Ruch et al., 2017).

Several studies have reported the presence of common bacteria between human milk and infant stool. In fact, during the first month of life, breastfed infants share up to $28 \%$ of their fecal bacteria with their mother's milk bacteria as reported for Spanish, Canadian, Finnish, American and Italian populations (Martín et al., 2012; Azad et al., 2013; Jost et al., 2014; Pannaraj et al., 
400 2017; Ferretti et al., 2018). In this study, despite differences in the bacterial diversity between the 401 milk and stool samples, we observed the presence of 25 shared taxa in at least $50 \%$ of 402 mother-neonate pairs, which can be an indicator of vertical transmission. These 25 taxa 403 represent $40 \%$ of all detected bacterial OTUs (Fig 5); such as Staphylococcus, 404 Pseudomonadaceae, and Propionibacterium acnes (currently named Cutibacterium acnes, Rocha 405 Martin et al., 2019). Previous studies have revealed that during breastfeeding period, 406 Staphylococcus can reach the mammary gland from the gut (entero-mammary translocation) or 407 the source can be the maternal skin (retrograde flow), constituting the most dominant bacteria in 408 breast milk (Jiménez et al., 2008; Fernández et al., 2013; Urbaniak et al., 2014; Jiménez et al., 409 2015; Urbaniak et al., 2016). Other species which are normally present on adult skin such as 410 Propionibacterium acnes, Streptococcus, and Corynebacterium (Jiménez et al., 2008; Grice \& 411 Segre, 2011) were also abundant in human milk samples in our study. This is not surprising 412 considering that skin bacteria have access to the mammary ducts through the nipple (Ramsay et 413 al., 2004) and can spread within the mammary glands, independently of lactation (Urbaniak et 414 al., 2014), probably for this reason, these bacteria have been also observed in breast milk 415 collected aseptically (Hunt et al., 2011). Some of breastfeeding related taxa mentioned above, such as the family Bifidobacteriaceae have been reported as pioneers of the infant gut due to its ability to metabolize human milk oligosaccharides (HMOs) to proliferate (Yu et al., 2013), in

418 other cases the presence of the HMOs promote the growth of microorganisms as Staphylococcus (Hunt et al., 2012), while others like Propionibacterium, Staphylococcus, and Streptococcus use

420

421

422

423

424

425

426

427

428

429

430

431

432

433

434

435

436

437

438

439 lactose as energy source (Chassard de Wouters \& Lacroix, 2014). These bacteria, have also capacity to metabolize lactate to propionic acid, conditioning the gut environment for later colonizers as Faecalibacterium, Coprococcus, and Roseburia, which rely on the presence of short chain fatty acids (SCFA) for growth (Duncan et al., 2002). On the other hand, in our study some of the abundant bacterial taxa found in the human milk such as Rhodobacteraceae, Sphingomonadaceae and Phyllobacteriaceae, families were observed in low abundance in the corresponding stool; suggesting these bacteria are likely not abundant colonizers of the distal colon, at least in our samples. We believe members of these families may have a transient presence in this environment or they may reside in other anatomical parts of the GI tract. We hypothesize that the presence of these taxa is important for immunological stimulation during the early days of colonization.

In Mexico, mothers habitually do not thoroughly cleanse their breasts before breastfeeding. For this reason and because we wanted to know the bacterial composition transferred from mother to neonate during the process of breastfeeding, in our study the mothers did not clean their breast prior to sample collection. There are other published studies on the characterization of "Breastfeeding-associated microbiota" where the breast milk was collected without an aseptic cleaning procedure (Ward et al., 2013; Urbaniak et al., 2014; Sakwinska et al., 2016). Based on our results, we think that in addition to intrinsic bacteria from the human milk, skin-associated taxa are an additional source of bacteria in the studied neonates. On the other hand, the microbial 
440

441

442

443

444

445

446

447

448

449

450

451

452

453

454

455

456

457

458

459

460

461

462

463

464

465

466

467

468

469

470

471

472

473

474

475

476

477

478

source tracker analysis indicated that breastfeeding microbiota was the main source of bacteria in most of the fecal samples of neonates, where only eight samples showed a total predominance of bacteria identified as "unknown source" (Fig 6A and S6). The source of these "unknown" bacteria may be the maternal gastrointestinal tract and the intrauterine environment such as placenta and amniotic fluid, which are mainly dominated by members of the orders Clostridiales, Bacteroidales, Lactobacillales, and Enterobacteriales (Parnell et al., 2017). Likewise, the delivery mode could also contribute to the abundance of these taxa. The fetal gut is exposed to these bacteria because large quantities of amniotic fluid are swallowed during the last stage of pregnancy (Neu \& Rushing, 2011); in fact, a recent study showed a high degree of similarity between meconium bacteria and those found in amniotic fluid (Ardissone et al., 2014). We can speculate that this microbial profile changes gradually after the birth due to the incorporation of new bacterial members mainly transferred through breastfeeding.

The delivery mode has been one of the most studied perinatal factors due to its potential effect on milk microbiota, as well as on the neonatal gut microbiota composition. Studies conducted in Spanish, Italian (Khodayar-Pardo et al., 2014; Cabrera-Rubio et al., 2016; Toscano et al., 2017) and Chinese (Li et al., 2017) populations, have reported significant differences in milk microbial profiles between mothers who delivered vaginally and those who delivered by C-section. Conversely, in a report by Urbaniak and coworkers (2016), no differences were identified in a Canadian population. In our study, we did not find association between breast milk microbiota composition and the delivery mode, which can be explained because in our cohort we had only women with non-elective $\mathrm{C}$-sections; the reported changes in the milk microbial communities appear to be more pronounced in women undergoing elective, than non-elective $\mathrm{C}$-sections (Cabrera-Rubio et al., 2012). The same group also reported that milk microbiota of women who gave birth by non-elective $\mathrm{C}$-section was comparable to women who delivered vaginally (Cabrera-Rubio et al., 2016). They suggest that physiological (e. g. hormonal) changes produced in the mother during the labor process, may influence the composition of the bacterial community. On the other hand, in our work the delivery mode had an impact on the infant gut microbiota composition. C-section delivery was associated with larger infant gut microbiota diversity and richness. Unlike our findings, most reports have shown lower diversity and abundance of gut microbiota during the first month of life in newborns born by C-section (Penders et al., 2006; Lee et al., 2016). Regarding Staphylococcus, Propionibacterium, Clostridium, and Corynebacterium genera, several authors have found higher abundance in meconium obtained from C-section neonates in accordance with our findings (Dominguez-Bello et al., 2010; Liu et al., 2015). The abundance of Bacteroides and Bifidobacterium genera on the other hand, has been reported to be decreased in C-section delivered infants (Montoya-Williams et al., 2018). In accordance with this, we observed a tendency of depletion for these genera in the $\mathrm{C}$-section stool samples of this work, but without statistical significance. Our results suggest that the delivery mode markedly modulates the gut microbiota composition in the newborn from the 
479 first days of life, being exposed to bacteria from the mother's skin and vaginal canal microbiota,

480 as well as non-maternal sources at the hospital environment.

481

482

483

484

485

486

487

488

489

490

491

492

493

494

495

496

497

498

499

500

501

502

503

504

505

506

507

508

509

510

511

512

513

514

515

516

517

518

The metagenomic predictions analyses of our data disclosed higher abundance of bacterial metabolic pathways related to fatty acids metabolism, peroxisomes, and PPAR signaling pathways, in breast milk in comparison to neonatal stool samples. Lipids provide the major portion $(45 \%-55 \%)$ of the total energy content of human milk, contributing to up to $90 \%$ of the energy required by exclusively breastfed infants during the first 6 months of life (Brenna \& Lapillonne, 2009; Koletzko et al., 2011); with the peroxisomes being one of the main specialized cellular organelles where fatty acid metabolism occurs (Wanders et al., 2016). Therefore, the high content of lipids present in human milk, could not only depend on the mother's endogenous mammary alveolar fatty acids synthesis, but also it may depend on the contribution of short chain fatty acids as acetate and lactate, produced by some bacteria of the milk microbiota (Henrick et al. 2018). It is known that butyrate and propionate participate not only in the regulation of lipid metabolism, but also have a role in the regulation of immune responses and inflammation through activation of the peroxisome proliferator-activated receptors (PPAR) (Nepelska et al., 2017; Hasan et al., 2019).

Neonates showed a high abundance of metabolic pathways in the gut microbiota related to carbohydrate metabolism. Several studies have reported that Bifidobacteria - whose abundance is significantly larger in our neonate samples — can metabolize a wide variety of carbohydrates, such as lactose, the main sugar of human milk (Table 3). In addition, Bifidobacteria can also degrade lactate anaerobically to pyruvate, to generate energy through the pentose phosphate pathway (Wolfe, 2015). This metabolic adaptation of Bifidobacteria to sugar-rich environments such as breast milk, is due to its $5.5 \%$ of genomic sequences associated to the metabolism of carbohydrates (Milani et al., 2015). Likewise, in the neonatal stool, an abundance of genes involved in the vitamin B6 (pyridoxine) metabolism was detected. The production of B-vitamins has been also associated to bacteria such as Bifidobacterium and Acinetobacter (Magnúsdóttir et al., 2015). Beyond its role as a necessary cofactor in the folate cycle, vitamin B6 also plays an important role in amino acid metabolism, the synthesis of neurotransmitters and the hormone melatonin (Rossi et al., 2011). Metabolic pathways involved in bacterial colonization and proliferation, such as bacterial secretion system and bacterial chemotaxis as well as antigens presentation, were also over-represented in neonatal stool. Besides the interaction of bacteria with the host, these functions are essential for the gradual colonization of the immature neonatal gut. Adhesion to the intestinal mucosa is an important feature for bacteria who colonize the gut (González-Rodríguez et al., 2013). This study provides the first results on breast milk microbiota obtained under physiological conditions in healthy Mexican mothers, and its association on the early colonization of the neonatal gut, as well as the effect of delivery mode on the breast milk and neonatal stool microbiota. 
519 Our study has the following limitations with respect to the environmental variables, we could not 520 obtain the maternal information related to dietary habits during pregnancy, which could be 521 relevant to the breast milk microbial profiles. Although the core microbiome and microbial 522 source trackers analysis showed evidence about the shared bacterial taxa and the vertical transfer 523 of the microbiota from mother to child, the presence of common taxa does not necessarily 524 validate the vertical transmission, since the species could a have a different source of origin, or 525 identified taxa in different niches (breast milk and neonate gut) not necessarily are the same. 526 Therefore, this result must be confirmed evaluating whether shared bacteria belong to the same 527 strain. Similarly, the origin of these bacteria is equally important, especially to know which 528 strain comes from the mother gut and which come from the breast skin, as well as to determine

529

530

531

532

533

\section{Conclusions}

535 Our study provides evidence that the human milk is one of the main sources of bacteria that 536

537

538

539

540

541

542

543

544

545

546

547

548

549

550

551

552

553

554

555

556

557

558 the magnitude of these contributions in the gut colonization of the newborn. However, we neither collected stool nor breast skin samples from the mother. Additionally, there is a possibility that the specialized kit method used to extract DNA from each type of sample (human milk, stool) affects the microbial composition. colonize the neonatal gastrointestinal tract from the first days of life. This gut colonization is characterized by a high dominance of bacterial taxa, mainly by members of the phyla Firmicutes (Clostridium gasigenes, Streptococcus, Staphylococcus, and Enterococcus), Proteobacteria (Pseudomonadaceae, Sphingomonadaceae, and Bradyrhizobiaceae), Actinobacteria (Bifidobacterium, and Propionibacterium acnes) and Bacteroidetes (Bacteroides), which may be transferred through lactation, while other taxa in minor proportion such as Clostridiales could come from other sources. Likewise, perinatal factors such as delivery mode suggest an association with the gut microbiota composition in the neonates. Finally, we found a higher abundance of predicted bacterial metabolic pathways associated with lipid metabolism in human milk, while in the neonates the functional pathways are more associated to carbohydrate metabolism and bacterial colonization. This study contributes to the knowledge on human milk and neonatal stool microbiota in healthy Mexican population and supports the idea of vertical mother-neonate transmission through exclusive breastfeeding.

\section{Acknowledgements}

We are grateful to Flor María Galván-Rodríguez, Carolina Miranda-Brito, Francisco Guillermo Borques-Arreortua and Rodrigo García-Gutiérrez for support in the lab work and in sample collection; Alma Lemus-Hernández, and Viridiana Rosas-Ocegueda for administrative assistance; and Tania Smith Marquez for English edition of first draft. The authors are deeply indebted to all the participant mothers and babies of this study.

\section{References}


559 Aagaard K, Ma J, Antony KM, Ganu R, Petrosino J, Versalovic J. 2014. The placenta harbors a 560 unique microbiome. Science Translational Medicine 6: 237ra65-237ra65.

561 https://doi.org/10.1126/scitranslmed.3008599.

562

563 Ardissone AN, de la Cruz DM, Davis-Richardson AG, Rechcigl KT, Li N, Drew JC, Murgas-

564 Torrazza R, Sharma R, Hudak ML, Triplett EW, Neu J. 2014. Meconium microbiome analysis

565 identifies bacteria correlated with premature birth. PLOS ONE 9:e90784.

566 https://doi.org/10.1371/journal.pone.0090784.

567

568 Asnicar F, Manara S, Zolfo M, Truong DT, Scholz M, Armanini F, Ferretti P, Gorfer V, Pedrotti 569 A, Tett A, Segat N. 2017. Studying vertical microbiome transmission from mothers to infants by 570 strain-level metagenomic profiling. mSystems 2:1-13. https://doi.org/10.1128/mSystems.00164$571 \underline{16}$.

572

573 Atarashi K, Tanoue T, Shima T, Imaoka A, Kuwahara T, Momose Y, Cheng G, Yamasaki S, 574 Saito T, Ohba Y, Taniguchi T, Takeda K, Hori S, Ivanov II, Umesaki Y, Itoh K, Honda K. 2011. 575 Induction of colonic Regulatory T cells by indigenous Clostridium species. Science 331:337576 341. https://doi.org/10.1126/science.1198469.

577

578 Azad MB, Konya T, Maughan H, Guttman DS, Field CJ, Chari RS, Sears MR, Becker AB, Scott 579 JA, Kozyrskyj AL. 2013. Gut microbiota of healthy Canadian infants: profiles by mode of 580 delivery and infant diet at 4 months. Canadian Medical Association Journal 185:385-394.

581 https://doi.org/10.1503/cmaj.121189.

582

583

Biagi E, Quercia S, Aceti A, Beghetti I, Rampelli S, Turroni S, Faldella G, Candela M, Brigidi P, 584 Corvaglia L. 2017. The bacterial ecosystem of mother's milk and infant's mouth and gut.

585 Frontiers in Microbiol 8:1-9. https://doi.org/10.3389/fmicb.2017.01214.

586

587 Borderon E, Thieffry JC, Jamet O, Poisson D, Boisseau C, Farid IA. 1990. Observations on the 588 intestinal colonization by Pseudomonas aeruginosa in newborn infants. Neonatology 57:88-97.

589 https://doi.org/10.1159/000243168.

590

591 Bottacini F, van Sinderen D, Ventura M. 2017.Omics of Bifidobacteria: research and insights

592 into their health-promoting activities. Biochemical Journal 474:4137-4152.

593 https://doi.org/10.1042/BCJ20160756.

594

595 Brenna JT, Lapillonne A. 2009. Background paper on fat and fatty acid requirements during 596 pregnancy and lactation. Annals of Nutrition \& Metabolism 55:97-122.

597 https://doi.org/10.1159/000228998.

598 
599 Cabrera-Rubio R., Collado M. C., Laitinen K., Salminen S., Isolauri E., \& Mira A. 2012. The

600 human milk microbiome changes over lactation and is shaped by maternal weight and mode of

601 delivery. The American Journal of Clinical Nutrition, 96(3), 544-551.

602 https://doi.org/10.3945/ajcn.112.037382.

603

604 Cabrera-Rubio R, Mira-Pascual L, Mira A, Collado MC. 2016. Impact of mode of delivery on

605 the milk microbiota composition of healthy women. Journal of Developmental Origins of Health

606 and Disease 7:54-60. https://doi.org/10.1017/S2040174415001397.

607

608 Caporaso JG, Kuczynski J, Stombaugh J, Bittinger K, Bushman FD, Costello EK, Fierer N, Peña 609 AG, Goodrich JK, Gordon JI, Gordon JL, Huttley GA, Kelley ST, Knights D, Koenig JE, Ley

610 RE, Lozupone CA, McDonald D, Muegge BD, Pirrung M, Reeder J, Sevinsky JR, Turnbaugh PJ, 611 Walters WA, Widmann J, Yatsunenko T, Zaneveld J, Knight R. 2010. QIIME allows analysis of 612 high-throughput community sequencing data. Nature Methods 7:335-336.

613 https://doi.org/10.1038/nmeth.f.303.

614

615 Chan AA, Bashir M, Rivas MN, Duvall K, Sieling PA, Pieber TR, Vaishampayan PA, Love SM, 616 Lee DJ. 2016. Characterization of the microbiome of nipple aspirate fluid of breast cancer

617 survivors. Scientific Reports 6:1-12. https://doi.org/10.1038/srep28061.

618

619 Chassard, C., de Wouters, T., \& Lacroix, C. (2014). Probiotics tailored to the infant: A window 620 of opportunity. Current Opinion in Biotechnology, 26, 141-147.

621 https://doi.org/10.1016/j.copbio.2013.12.012

622

623

624

Chávez-Carbajal A, Nirmalkar K, Pérez-Lizaur A, Hernández-Quiroz F, Ramírez-del-Alto S,

625 García-Mena J, Hernández-Guerrero C. 2019. Gut microbiota and predicted metabolic pathways

626 in a sample of Mexican women affected by obesity and obesity plus metabolic syndrome.

627

628 International Journal Molecular Sciences 20:438. https://doi.org/10.3390/ijms20020438.

629

Collado MC, Rautava S, Aakko J, Isolauri E, Salminen S. 2016. Human gut colonization may be initiated in utero by distinct microbial communities in the placenta and amniotic fluid. Scientific

630 Reports 6:23129. https://doi.org/10.1038/srep23129.

631

632

Colliou N, Ge Y, Sahay B, Gong M, Zadeh M, Owen JL, Neu J, Farmerie WG, Alonzo F, Liu K,

633 Jones DP, Li S, Mohamadzadeh M. 2017. Commensal Propionibacterium strain UF1 mitigates

634 intestinal inflammation via Th17 cell regulation. The Journal of Clinical Investigation 127:3970-

635 3986. DOI:10.1172/JCI95376.

636

637 Consejo Nacional de Evaluación de la Política de Desarrollo Social (CONEVAL). Pobreza

638 municipal 2010-2015. Available at https://www.coneval.org.mx/Medicion/Paginas/Pobreza639 municipal.aspx (accessed 20 May 2019). 
640

641 Cynkin MA \& Delwiche EA. 1958. Metabolism of pentoses by Clostridia. I. Enzymes of ribose

642 dissimilation in extracts of Clostridium perfringens. Journal of Bacteriology 75:331-334.

643

644 D’Auria G, Peris-Bondia F, Džunková M, Mira A, Collado MC, Latorre A, Moya A. 2013.

645 Active and secreted IgA-coated bacterial fractions from the human gut reveal an under-

646 represented microbiota core. Scientific Reports 3:3515. https://doi.org/10.1038/srep03515.

647

648 Davé V, Street K, Francis S, Bradman A, Riley L, Eskenazi B, Holland N. 2016. Bacterial

649 microbiome of breast milk and child saliva from low-income Mexican-American women and

650 children. Pediatric RESEARCH 79:846-854. https://doi.org/10.1038/pr.2016.9.

651

652

Dekio I, Hayashi H, Sakamoto M, Kitahara M, Nishikawa T, Suematsu M, Benno Y. 2005.

653 Detection of potentially novel bacterial components of the human skin microbiota using culture-

654 independent molecular profiling. Journal of Medical Microbiology 54:1231-1238.

655 https://doi.org/10.1099/jmm.0.46075-0.

656

657

Dominguez-Bello MG, Costello EK, Contreras M, Magris M, Hidalgo G, Fierer N, Knight R.

658 2010. Delivery mode shapes the acquisition and structure of the initial microbiota across multiple 659 body habitats in newborns. Proceeding of the National Academy of Sciences of the United States

660 of America 107:11971-11975. https://doi.org/10.1073/pnas.1002601107.

661

662 Donnet-Hughes A, Perez PF, Doré J, Leclerc M, Levenez F, Benyacoub J, Serrant P, Segura-

663 Roggero I, Schiffrin EJ. 2010. Potential role of the intestinal microbiota of the mother in

664 neonatal immune education. Proceeding of the Nutrition Society 69:407-415.

665 https://doi.org/10.1017/S0029665110001898.

666

667

668

Duncan SH, Barcenilla A, Stewart CS, Pryde SE, Flint HJ. 2002. Acetate utilization and butyryl

669 coenzyme A (CoA): acetate-CoA transferase in butyrate-producing bacteria from the human

670 large intestine. Applied and Environmental Microbiology 68:5186-5190.

671

672 FastQC A quality control application for high throughput sequence data. Available at

673 https://www.bioinformatics.babraham.ac.uk/projects/fastqc/ (accessed 21 May 2019).

674

675 Fernández L, Langa S, Martín V, Maldonado A, Jiménez E, Martín R, Rodríguez JM. 2013. The 676 human milk microbiota: origin and potential roles in health and disease. Pharmacology Research 677 69:1-10. https://doi.org/10.1016/j.phrs.2012.09.001.

678 
679 Ferretti P, Pasolli E, Tett A, Asnicar F, Gorfer V, Fedi S, Armanini F, Truong DT, Manara S, 680 Zolfo M, Beghini F, Bertorelli R, De Sanctis V, Bariletti I, Canto R, Clmenti R, Cologna M, 681 Crifo T, Cusumano G, Gottardi S, Innamorati C, Masé C, Postai D, Savoi D, Duranti S, Lugli 682 GA, Mancabelli L, Turroni F, Ferrario C, Milani C, Mangifesta M, Anzolone R, Viappiani A, 683 Yassour M, Vlamakis H, Collado CM, Koren O, Tateo S, Soffiati M, Pedrotti A, Ventura M, 684 Huttenhower C, Bork P, Segata N. 2018. Mother-to-infant microbial transmission from different 685 body sites shapes the developing infant gut microbiome. Cell Host \& Microbe 24:133-145.e5. 686 https://doi.org/10.1016/j.chom.2018.06.005.

687

688 Fierer N, Hamady M, Lauber CL, Knight R. 2008. The influence of sex, handedness, and 689 washing on the diversity of hand surface bacteria. Proceeding of the National Academy of 690 Sciences of the United States of America 105:17994-17999.

691 https://doi.org/10.1073/pnas.0807920105.

692

Fitzstevens JL, Smith KC, Hagadorn JI, Caimano MJ, Matson AP, Brownell EA. 2017.

694 Systematic review of the human milk microbiota. Nutrition in Clinical Practice 32:354-364.

695 https://doi.org/10.1177/0884533616670150.

696

697

Gomez-Gallego C, Garcia-Mantrana I, Salminen S, Collado M. C. 2016. The human milk

698 microbiome and factors influencing its composition and activity. Seminars in Fetal and Neonatal 699 Medicine 21:400-405. https://doi.org/10.1016/j.siny.2016.05.003.

700

701

González-Rodríguez I, Ruiz L, Gueimonde M, Margolles A, Sánchez B. 2013. Factors involved

702 in the colonization and survival of bifidobacteria in the gastrointestinal tract. FEMS

703 Microbiology Letters 340:1-10. https://doi.org/10.1111/1574-6968.12056.

704

705

706

Grice EA, Segre JA. 2011. The skin microbiome. Nature Reviews Microbiology 9:244-253. https://doi.org/10.1038/nrmicro2537.

707

708

Grönlund MM, Gueimonde M, Laitinen K, Kociubinski G, Grönroos T, Salminen S, Isolauri E.

709 2007. Maternal breast-milk and intestinal bifidobacteria guide the compositional development of

710 the Bifidobacterium microbiota in infants at risk of allergic disease. Clinical \& Experimental

711 Allergy 37:1764-1772. https://doi.org/10.1111/j.1365-2222.2007.02849.x.

712

713 Hasan A, Rahman A, Kobori H. 2019. Interactions between host PPARs and gut microbiota in

714 health and disease. International Journal of Molecular Sciences 20:387.

715 https://doi.org/10.3390/ijms20020387.

716

717 Henrick BM, Hutton AA, Palumbo MC, Casaburi G, Mitchell RD, Underwood MA, Smilowitz 718 JT, Frese SA. 2018. Elevated fecal pH indicates a profound change in the breastfed infant gut 
719 microbiome due to reduction of Bifidobacterium over the past century. mSphere. 3(2). pii:

720 e00041-18. doi: 10.1128/mSphere.00041-18. eCollection 2018 Mar-Apr.

721

722 Hieken TJ, Chen J, Hoskin TL, Walther-Antonio M, Johnson S, Ramaker S, Xiao J, Radisky DC,

723 Knutson KL, Kalari KR, Yao JZ, Baddour LM, Chia N, Degnim AC. 2016. The microbiome of

724 aseptically collected human breast tissue in benign and malignant disease. Scientific Reports

725 6:30751. https://doi.org/10.1038/srep30751.

726

727 Hunt KM, Foster JA, Forney LJ, Schütte UME, Beck DL, Abdo Z, Fox LK., Williams JE,

728 McGuire MK, McGuire MA. 2011. Characterization of the diversity and temporal stability of

729 bacterial communities in human milk. PLOS ONE 6:e21313.

730 https://doi.org/10.1371/journal.pone.0021313.

731

732 Hunt KM, Preuss J, Nissan C, Davlin CA, Williams JE, Shafii B, Richardson AD, McGuire MK, 733 Bode L, McGuire MA. 2012. Human milk oligosaccharides promote the growth of

734 Staphylococci. Applied and Environmental Microbiology 78:4763-4770.

735 https://doi.org/10.1128/aem.00477-12.

736

737

INEGI. 2019. Available at https://www.inegi.org.mx/app/areasgeograficas/default.aspx

738 (accessed 20 May 2019).

739

740 Jiménez E, Delgado S, Maldonado A, Arroyo R, Albújar M, García N, Jariod M, Fernández L,

741 Gómez A, Rodríguez JM. 2008. Staphylococcus epidermidis: A differential trait of the fecal

742 microbiota of breast-fed infants. BMC Microbiology 8: 143. https://doi.org/10.1186/1471-2180-

$743 \underline{8-143}$.

744

745 Jiménez E, de Andrés J, Manrique M, Pareja-Tobes P, Tobes R, Martínez-Blanch J F, Codoñer

746 FM, Ramón D, Fernández L, Rodríguez JM. 2015. Metagenomic analysis of milk of healthy and

747 mastitis-suffering women. Journal of Human Lactation 31:406-415.

748 https://doi.org/10.1177/0890334415585078.

749

750 Jost T, Lacroix C, Braegger CP, Rochat F, Chassard C. 2014. Vertical mother-neonate transfer of 751 maternal gut bacteria via breastfeeding. Environmental Microbiology 16:2891-2904.

752 https://doi.org/10.1111/1462-2920.12238.

753

754 Kamada N, Seo S-U, Chen GY, Núñez G. 2013. Role of the gut microbiota in immunity and 755 inflammatory disease. Nature Reviews Immunology 13:321-335. https://doi.org/10.1038/nri3430. 
757 Khodayar-Pardo P, Mira-Pascual L, Collado MC, Martínez-Costa C. 2014. Impact of lactation 758 stage, gestational age and mode of delivery on breast milk microbiota. Journal of Perinatology 759 34:599-605. https://doi.org/10.1038/jp.2014.47.

760

761 Knights D, Kuczynski J, Charlson ES, Zaneveld J, Mozer MC, Collman RG, Bushman FD, 762 Knight R, Kelley ST. 2011. Bayesian community-wide culture-independent microbial source

763

764

765

766

767

768

769

770

771

772

773

774

775

776

777

778

779

780

781

782

783

784

785

786

787

788

789

790

791

792

793

794

795 tracking. Nature Methods 8:761-763. https://doi.org/10.1038/nmeth.1650.

Koletzko B, Agostoni C, Bergmann R, Ritzenthaler K, Shamir R. 2011. Physiological aspects of human milk lipids and implications for infant feeding: A workshop report. Acta Paediatrica 100:1399-1400. https://doi.org/10.1111/j.1651-2227.2011.02451.x.

Kumar H, du Toit E, Kulkarni A, Aakko J, Linderborg KM, Zhang Y, Nicol MP, Isolauri E, Yang B, Collado MC, Salminen S. 2016. Distinct patterns in human milk microbiota and fatty acid profiles across specific geographic locations. Frontiers in Microbiology 7:1619.

https://doi.org/10.3389/fmicb.2016.01619.

Lackey KA, Williams JE, Meehan CL, Zachek JA, Benda ED, Price WJ, Foster JA, Sellen DW, Kamau-Mbuthia EW, Kamundia EW, Moore S, Prentice AM, Gindola D, Kvist LJ, Otoo GE, García-Carral C, Jiménez E, Ruiz L, Rodríguez JM, Pareja RG, Bode L, McGuire MA, McGuire MK. 2019. What's Normal? microbiomes in human milk and infant feces are related to each other but vary geographically: The INSPIRE Study. Frontiers in Nutrition 6 https://doi.org/10.3389/fnut.2019.00045.

Langille MGI, Zaneveld J, Caporaso JG, McDonald D, Knights D, Reyes JA, Clemente JC, Burkepile DE, Vega Thurber RL, Knight R, Beiko RG, Huttenhower C. 2013. Predictive functional profiling of microbial communities using $16 \mathrm{~S}$ rRNA marker gene sequences. Nature Biotechnology 31:814-821. https://doi.org/10.1038/nbt.2676.

LaTuga M, Stuebe A, Seed PA. 2014. Review of the source and function of microbiota in breast milk. Seminars in Reproductive Medicine 32:068-073. https://doi.org/10.1055/s-0033-1361824.

Lee E, Kim B-J, Kang M-J, Choi KY, Cho H-J, Kim Y, Yang SI, Jung Y-H, Kim HY, Seo J-H, Kwon J-W, Kim H-B, Lee S-Y, Hong S-Y. 2016. Dynamics of gut microbiota according to the delivery mode in healthy Korean infants. Allergy Asthma et Immunology Research 8:471-477. https://doi.org/10.4168/aair.2016.8.5.471.

Li S-W, Watanabe K, Hsu C-C, Chao S-H, Yang Z-H, Lin Y-J, Chen C-C, Cao Y-M, Huang HC, Chang C-H, Tsai Y-C. 2017. Bacterial composition and diversity in breast milk samples from 
796 mothers living in Taiwan and mainland China. Frontiers in Microbiology 8: 1-15.

797 https://doi.org/10.3389/fmicb.2017.00965.

798

799

800

801

802

803

804

805

806

807

808

809

810

811

812

813

814

815

816

817

818

819

820

821

822

823

824

825

826

827

828

829

830

831

832

833

834
Liu D, Yu J, Li L, Ai Q, Feng J, Song C, Li H. 2015. Bacterial community structure associated with elective cesarean section versus vaginal delivery in Chinese newborns. Journal of Pediatric Gastroenterology and Nutrition 60:240-246. https://doi.org/10.1097/MPG.0000000000000606.

Long X, Deng S, Mattner J, Zang Z, Zhou D, McNary N, Goff RD, Teyton L, Bendelac A, Savage PB. 2007. Synthesis and evaluation of stimulatory properties of Sphingomonadaceae glycolipids. Nature Chemical Biology 3:559-564. https://doi.org/10.1038/nchembio.2007.19.

Lundell A-C, Hesselmar B, Nordström I, Saalman R, Karlsson H, Lindberg E, Åberg N, Adlerberth I, Wold AE, Rudin A. 2009. High circulating immunoglobulin A levels in infants are associated with intestinal toxigenic Staphylococcus aureus and a lower frequency of eczema. Clinical \& Experimental Allergy 39:662-670. https://doi.org/10.1111/j.1365-2222.2008.03176.x.

Magnúsdóttir S, Ravcheev D, de Crécy-Lagard V, Thiele I. 2015. Systematic genome assessment of B-vitamin biosynthesis suggests co-operation among gut microbes. Frontiers in Genetics 6 https://doi.org/10.3389/fgene.2015.00148.

Martín V, Maldonado-Barragán A, Moles L, Rodriguez-Baños M, Campo R Del, Fernández L, Rodríguez JM, Jiménez E. 2012. Sharing of bacterial strains between breast milk and infant feces. Journal of Human Lactation 28:36-44. https://doi.org/10.1177/0890334411424729.

McFarland J, Hussar B, Wang X, Zhang J, Wang K, Rathbun A, Barmer A, Forrest Cataldi E, Bullock Mann F. 2018. The condition of education 2018 (NCES 2018-144). U.S. Dep. Educ 188-190. https://doi.org/NCES 2018144.

Milani C, Lugli GA, Duranti S, Turroni F, Mancabelli L, Ferrario C, Mangifesta M, Hevia A, Viappiani A, Scholz M, Arioli S, Sanchez B, Lane J, Ward DV, Hickey R, Mora D, Segata N, Margolles A, Sinderen D van, Ventura M. 2015. Bifidobacteria exhibit social behavior through carbohydrate resource sharing in the gut. Scientific Reports 5:15782. https://doi.org/10.1038/srep15782.

Montoya-Williams D, Lemas DJ, Spiryda L, Patel K, Carney OO, Neu J, Carson TL. The neonatal microbiome and its partial role in mediating the association between birth by cesarean section and adverse pediatric outcomes. Neonatology. 2018;114(2):103-111. doi: 10.1159/000487102. Epub 2018 May 22. 
835 Moossavi S, Sepehri S, Robertson B, Bode L, Goruk S, Field CJ, Lix LM, de Souza R J, Becker 836 AB, Mandhane PJ, Turkey SE, Subbarao P, Moraes TJ, Lefebvre DL, Sears MR, Khafipour E, 837 Azad MB. 2019. Composition and variation of the human milk microbiota Are are influenced by 838 maternal and early-life factors. Cell Host \& Microbe, 25:324-335.e4.

839 https://doi.org/10.1016/j.chom.2019.01.011.

840

841 Morrison DJ, Preston T. 2016. Formation of short chain fatty acids by the gut microbiota and 842 their impact on human metabolism. Gut Microbes 7:189-200.

843 https://doi.org/10.1080/19490976.2015.1134082.

844

845 Morrow AL, Lagomarcino AJ, Schibler KR, Taft DH, Yu Z, Wang B, Altaye M, Wagner M, 846 Gevers D, Ward DV, Kennedy MA, Huttenhower C, Newburg DS. 2013. Early microbial and 847 metabolomic signatures predict later onset of necrotizing enterocolitis in preterm infants.

848 Microbiome 1:13. https://doi.org/10.1186/2049-2618-1-13.

849

850 Mueller N, Shin H, Pizoni A, Werlang I, Matte U, Goldani M, Goldani H, Dominguez-Bello M. 2017. Delivery mode and the transition of pioneering gut-microbiota structure, composition and predicted metabolic function. Genes 8:364. https://doi.org/10.3390/genes8120364.

Murphy K, Curley D, O’Callaghan TF, O’Shea C-A, Dempsey EM, O’Toole PW, Ross RP, Ryan CA, Stanton C. 2017. The composition of human milk and infant faecal microbiota over

856 the first three months of life: A Pilot Study. Scientific Reports 7:40597.

857 https://doi.org/10.1038/srep40597.

858

859

Murugesan S, Ulloa-Martínez M, Martínez-Rojano H, Galván-Rodríguez FM, Miranda-Brito C, 860 Romano MC, Piña-Escobedo A, Pizano-Zárate ML, Hoyo-Vadillo C, García-Mena J. 2015.

861 Study of the diversity and short-chain fatty acids production by the bacterial community in 862 overweight and obese Mexican children. European Journal of Clinical Microbiology \&

863 Infectious Diseases 34:1337-1346. https://doi.org/10.1007/s10096-015-2355-4.

864

865 Nagpal R, Tsuji H, Takahashi T, Nomoto K, Kawashima K, Nagata S, Yamashiro Y. 2017.

866 Ontogenesis of the gut microbiota composition in healthy, full-term, vaginally born and breast-

867 fed infants over the first 3 years of life: A quantitative bird's-eye view. Frontiers in

868 Microbiology 8:1388. https://doi.org/10.3389/fmicb.2017.01388.

869

870 Nepelska M, De Wouters T, Jacouton E, Béguet-Crespel F, Lapaque N, Doré J, Arulampalam V, 871 Blottière HM. 2017. Commensal gut bacteria modulate phosphorylation-dependent PPAR $\lambda$

872 transcriptional activity in human intestinal epithelial cells. Scientific Reports 7:1-13.

873 https://doi.org/10.1038/srep43199.

874 
875 Neu J, Rushing J. 2011. Cesarean versus vaginal delivery: long-term infant outcomes and the

876 hygiene hypothesis. Clinics in Perinatology 38:321-331.

877 https://doi.org/10.1016/j.clp.2011.03.008.

878

879 Ozkan J, Willcox M, Wemheuer B, Wilcsek G, Coroneo M, Thomas T. 2019. Biogeography of 880 the human ocular microbiota. The Ocular Surface 17:111-118.

881 https://doi.org/10.1016/j.jtos.2018.11.005.

882

883 Pannaraj PS, Li F, Cerini C, Bender J M, Yang S, Rollie A, Adisetiyo H, Zabih S, Lincez PJ, 884 Bittinger K, Bailey A, Bushman FD, Sleasman J, Aldrovandi GM. 2017. Association between 885 breast milk bacterial communities and establishment and development of the infant gut 886 microbiome. JAMA Pediatric 171:647-654. https://doi.org/10.1001/jamapediatrics.2017.0378.

887

888

889

Parnell LA, Briggs CM, Cao B, Delannoy-Bruno O, Schrieffer AE, Mysorekar IU. 2017.

890

891

892 Microbial communities in placentas from term normal pregnancy exhibit spatially variable profiles. Scientific Reports 7:11200. https://doi.org/10.1038/s41598-017-11514-4.

893

894

895

896

897

898

899

900

901

902

903

904

905

906

907

908

909

910

911

912

913

Penders J, Thijs C, Vink C, Stelma FF, Snijders B, Kummeling I, van den Brandt PA, Stobberingh, EE. 2006. Factors influencing the composition of the intestinal microbiota in early infancy. Pediatrics 118:511-521. https://doi.org/10.1542/peds.2005-2824.

Ramsay DT, Kent JC, Owens RA, Hartmann PE. 2004. Ultrasound imaging of milk ejection in the breast of lactating women. Pediatrics 113:361-367. https://doi.org/10.1542/peds.113.2.361.

Rocha Martin VN, Schwab C, Krych L, Voney E, Geirnaert A, Braegger C, Lacroix C. 2019. Colonization of Cutibacterium avidum during infant gut microbiota establishment. FEMS Microbiology Ecology 95: 1-14. https://doi.org/10.1093/femsec/fiy215

Rossi M, Amaretti A, Raimondi S. 2011. Folate production by probiotic bacteria. Nutrients 3:118-134. https://doi.org/10.3390/nu3010118.

Ruch TR, Engel JN. 2017. Targeting the mucosal barrier: How pathogens modulate the cellular polarity network. Cold Spring Harbor Perspectives in Biology 9:a027953.

https://doi.org/10.1101/cshperspect.a027953.

Sakwinska O, Moine D, Delley M, Combremont S, Rezzonico E, Descombes P, Vinyes-Pares G, Zhang Y, Wang P, Thakkar SK. 2016. Microbiota in breast milk of Chinese lactating mothers. PLOS ONE 11:e0160856. https://doi.org/10.1371/journal.pone.0160856. 
914 Segata N, Izard J, Waldron L, Gevers D, Miropolsky L, Garrett WS, Huttenhower C. 2011.

915 Metagenomic biomarker discovery and explanation. Genome Biology 12:R60.

916 https://doi.org/10.1186/gb-2011-12-6-r60.

917

918 Shade A, Handelsman J. 2012. Beyond the Venn diagram: The hunt for a core microbiome.

919 Environmental Microbiology 14:4-12. https://doi.org/10.1111/j.1462-2920.2011.02585.x.

920

921 Shu M, Wang Y Yu, J Kuo, S Coda, A Jiang, Y Gallo RL, Huang CM. 2013. Fermentation of

922 Propionibacterium acnes, a commensal bacterium in the human skin microbiome, as skin

923 probiotics against methicillin-resistant Staphylococcus aureus. PLOS ONE 8

924 https://doi.org/10.1371/journal.pone.0055380.

925

926

927

Simpson MR, Avershina E, Storrø O, Johnsen R, Rudi, K, Øien, T. 2018. Breastfeeding-

928 associated microbiota in human milk following supplementation with Lactobacillus rhamnosus

929 GG, Lactobacillus acidophilus La-5, and Bifidobacterium animalis ssp. lactis Bb-12. Journal of Dairy Science 101:889-899. https://doi.org/10.3168/jds.2017-13411.

930

931

932

Stinson LF, Boyce MC, Payne MS, Keelan JA. 2019. The not-so-sterile womb: evidence that the

933 human fetus is exposed to bacteria prior to birth. Frontiers in Microbiology 10:1-15.

https://doi.org/10.3389/fmicb.2019.01124.

934

935 Tanaka M, Nakayama, J. 2017. Development of the gut microbiota in infancy and its impact on 936 health in later life. Allergology International 66:515-522.

937 https://doi.org/10.1016/j.alit.2017.07.010.

938

939

Toscano M, De Grandi R, Peroni DG, Grossi E, Facchin, V, Comberiati P, Drago L. 2017.

940 Impact of delivery mode on the colostrum microbiota composition. BMC Microbiology 17:205.

941 https://doi.org/10.1186/s12866-017-1109-0.

942

943 Turroni, F.; Serafini, F.; Mangifesta, M.; Arioli, S.; Mora, D.; van Sinderen, D.; Ventura, M.

944 Expression of sortase-dependent pili of Bifidobacterium bifidum PRL2010 in response to

945 environmental gut conditions. FEMS Microbiol. Lett., 2014, 357 (1), 23-33.

946 https://doi.org/10.1111/1574-6968.12509.

947

948 Urbaniak C, Angelini M, Gloor GB, Reid G. 2016. Human milk microbiota profiles in relation to

949 birthing method, gestation and infant gender. Microbiome 4:1. https://doi.org/10.1186/s40168-

$950 \quad$ 015-0145-y.

951 
952 Urbaniak C, Cummins J, Brackstone M, Macklaim JM, Gloor GB, Baban CK, Scott L, O’Hanlon 953 DM, Burton JP, Francis KP, Tangney M, Reid G. 2014. Microbiota of human breast tissue.

954 Applied and Environment Microbiology 80:3007-3014. https://doi.org/10.1128/aem.00242-14.

955

956 Wanders RJA, Waterham HR, Ferdinandusse S. 2016. Metabolic interplay between peroxisomes 957 and other subcellular organelles including mitochondria and the endoplasmic reticulum.

958 Frontiers in Cell and Development Biology 3:1-15. https://doi.org/10.3389/fcell.2015.00083.

959

960 Ward RE, Niñonuevo M, Mills DA, Lebrilla CB, and German JB. 2006. In Vitro Fermentation of 961 Breast Milk Oligosaccharides by Bifidobacterium infantis and Lactobacillus gasseri. Appl

962 Environ Microbiol 72(6): 4497-4499. doi: 10.1128/AEM.02515-05.

963

964 Ward TL, Hosid S, Ioshikhes I, Altosaar I. 2013. Human milk metagenome: A functional

965 capacity analysis. BMC Microbiology 13:116. https://doi.org/10.1186/1471-2180-13-116.

966

967 Wolfe AJ. 2015. Glycolysis for microbiome generation. Microbiology Spectrum 3:6072-6078.

968 https://doi.org/10.1128/microbiolspec.MBP-0014-2014.

969

970 Yu Z-T, Chen C, Kling DE, Liu B, McCoy JM, Merighi, M, Heidtman M, Newburg DS. 2013.

971 The principal fucosylated oligosaccharides of human milk exhibit prebiotic properties on

972 cultured infant microbiota. Glycobiology 23:169-177. https://doi.org/10.1093/glycob/cws138.

973 


\section{Figure 1}

Relative abundance of predominant bacterial taxa (phyla and families) in human milk and neonatal stool.

Abundance of each phylum in human milk (A) and neonatal stool (B). Comparison between groups was calculated using parametric t-test for paired samples followed by $\mathrm{BH}$ correction: Proteobacteria $(p=0.001, q=0.041)$; Firmicutes $(p=0.243, q=1.00)$; Actinobacteria $(p=$ 0.088, $q=1.00)$; Bacteroidetes $(p=0.009, q=0.185)$; Others $(p=0.598, q=1.00)$.

Relative abundance of dominant bacterial families for each group.

A

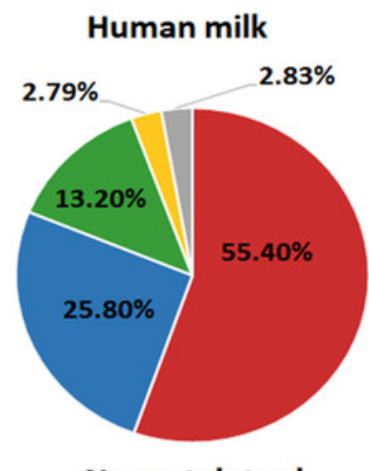

B

Neonatal stool

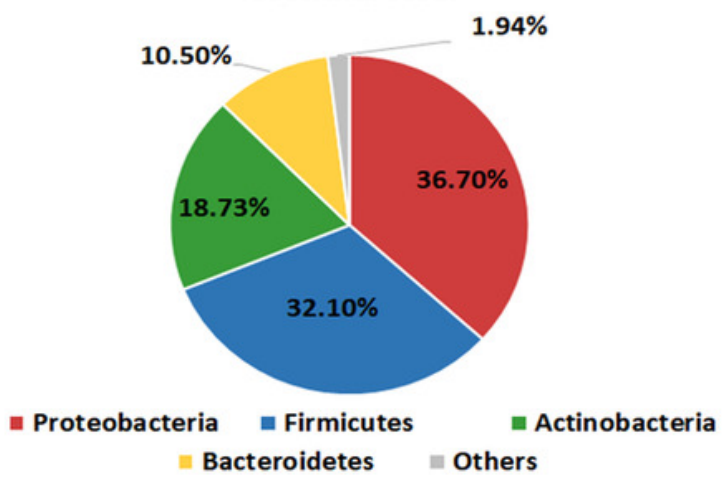

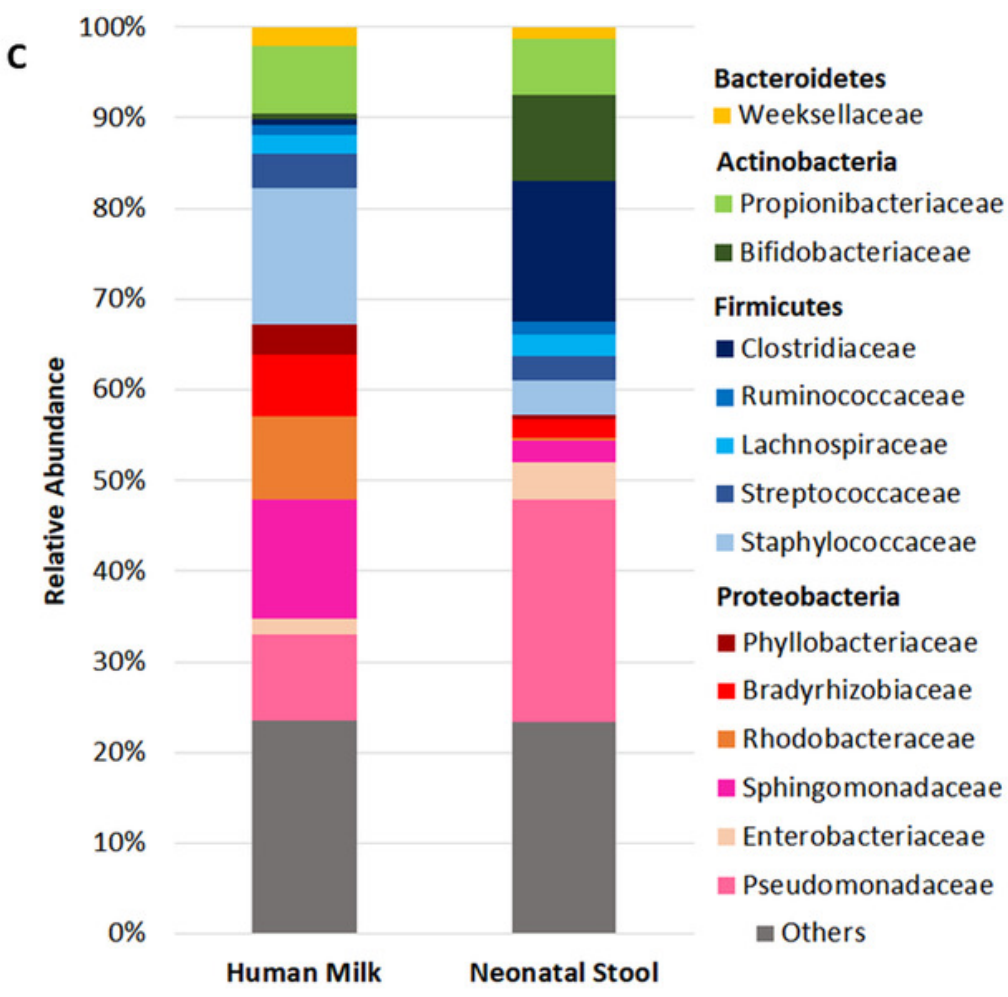


Figure 2

Linear discriminant analysis (LDA) effect size (LEfSe) comparison of differentially abundant bacterial taxa between human milk and neonatal stool.

Horizontal bars represent the effect size for each taxon: light blue color indicates taxa enriched in neonatal stool group, and crusta color indicates taxa enriched in milk group. LDA score cutoff of 3.5 was used to discriminate bacterial taxon. Statistically significant values are shown in Table S4. 


\section{Human_milk Neonatal_stool}

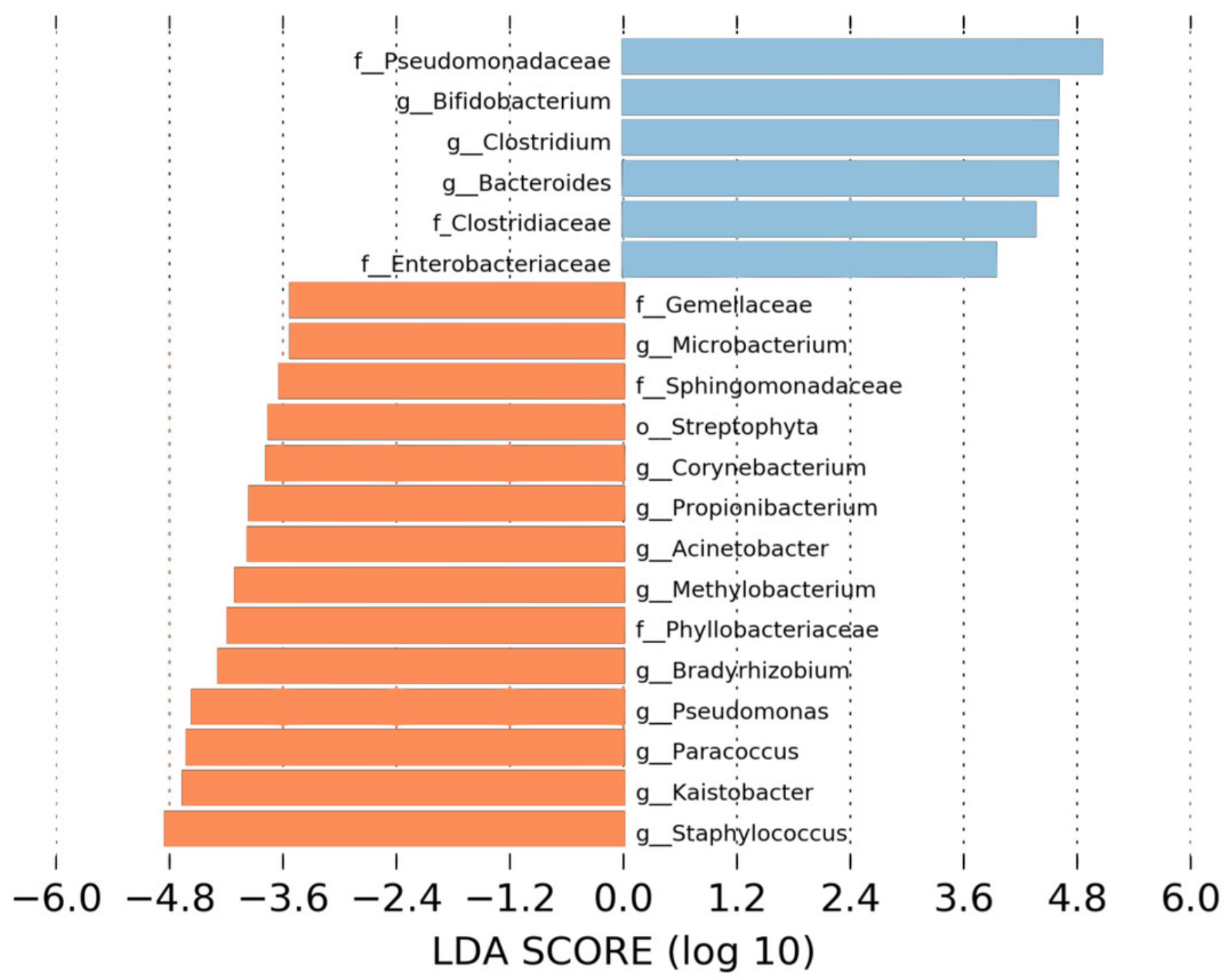




\section{Figure 3}

Bacterial diversity of human milk and neonatal stool microbiota.

Alpha diversity based on (A) observed number species $(p<0.001)$, (B) Chaol $(p<0.001)$, (C) Shannon $(p<0.001)$ and (D) Simpson $(p=0.006)$ indexes. Mann-Whitney U-test was used to find significant differences. Beta diversity analysis. Two-dimensional scatter plots were generate using PCoA based on unweighted Unifrac distance metric. (E) PC3 vs PC2, (F) $\mathrm{PC1}$ vs $\mathrm{PC2}$, and (G) PC1 vs PC3. Both groups significantly differed according to ANOSIM similarity test $(R=0.289, p=0.001)$ and Adonis statistical test $\left(R^{2}=0.949, p=0.001\right)$. Human milk samples $(n=67)$ are plotted as red dots and neonatal stool $(n=67)$ as blue dots. Statistically significant values are in Table $\mathrm{S} 5$. 


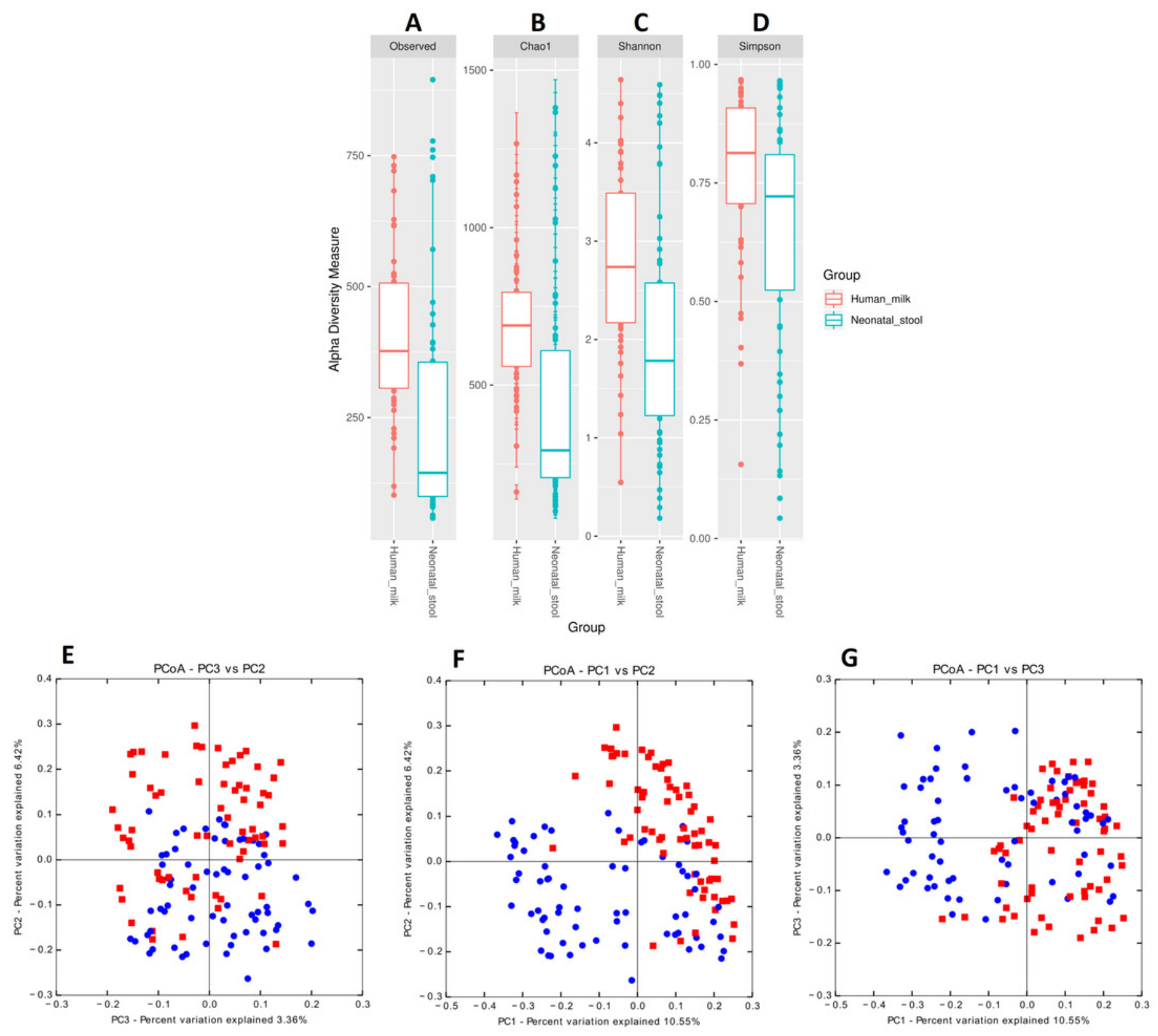


Figure 4

Alpha diversity in neonatal stool samples from neonates born by C-section $(n=19)$ or vaginal delivery mode $(n=41)$.

(A) Observed number species ( $p=0.003)$, (B) Chaol $(p=0.006)$, (C) Shannon $(p=0.046)$, and (D) Simpson ( $p=0.082$ ) indexes. The diversity indexes were calculated using Mann-Whitney $U$ test where $p<0.05$ was considered significant (Table S6). Labels beside the graphics indicates the delivery mode. 


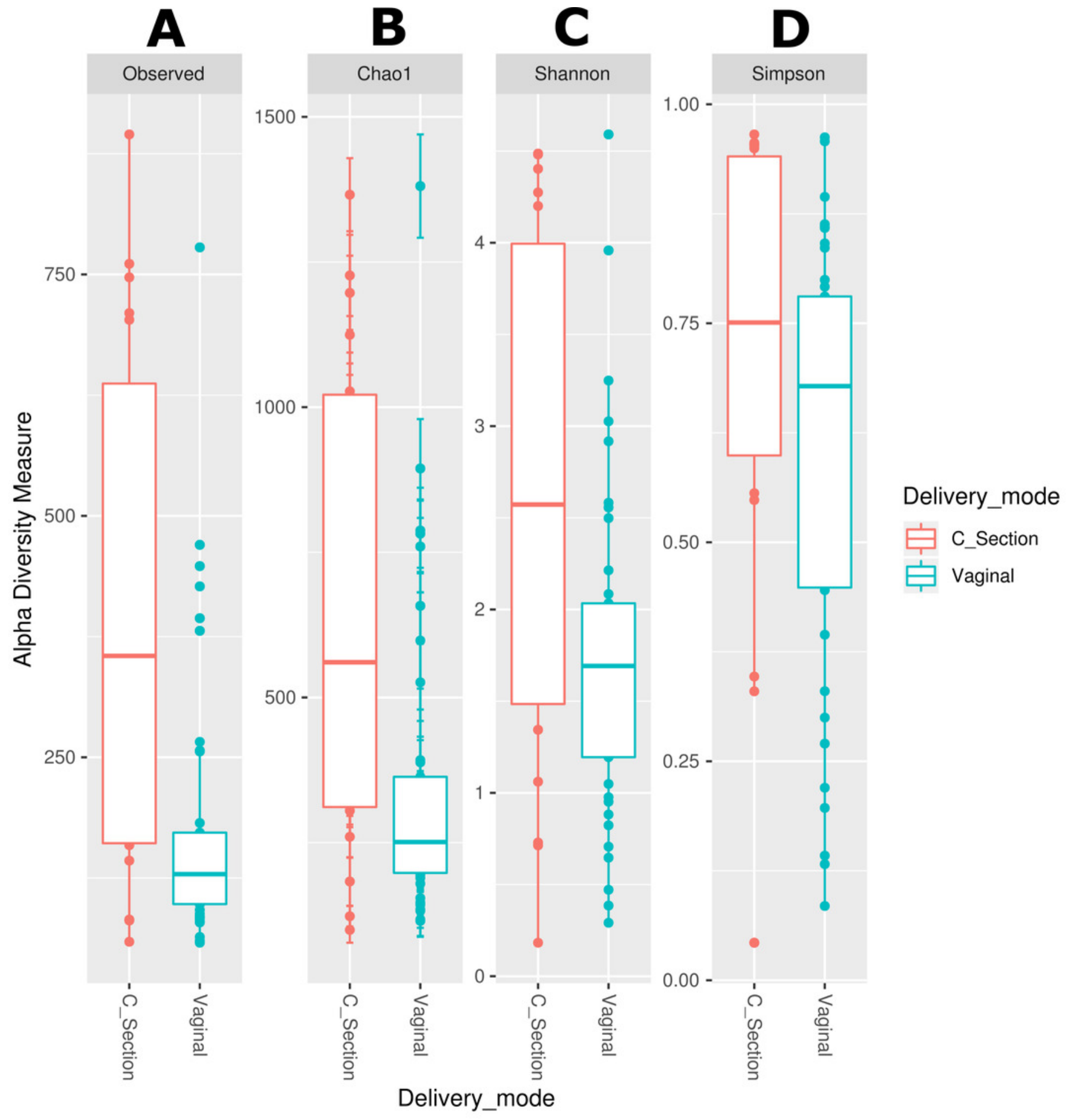




\section{Figure 5}

Analyses of shared OTUs in human milk/ neonatal stool and its abundance.

(A) Venn diagram showing unique and shared OTUs between human milk and neonatal stool samples. (B). Heatmap shows shared OTUs counts between taxa of human milk and neonatal stool groups. Included counts were present in at least $50 \%$ of paired samples and calculated by the compute_core_microbiome.py Qiime script. Color Key from green to red indicates increasing absolute abundance in natural logarithm of counts. Green color indicates lowest abundance while red color highest abundance, with taxa along the Y-axis and samples along X-axis.

A

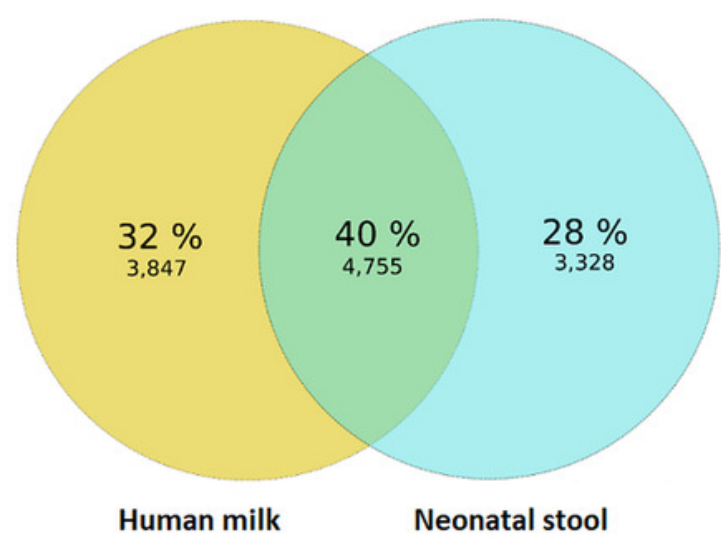

B

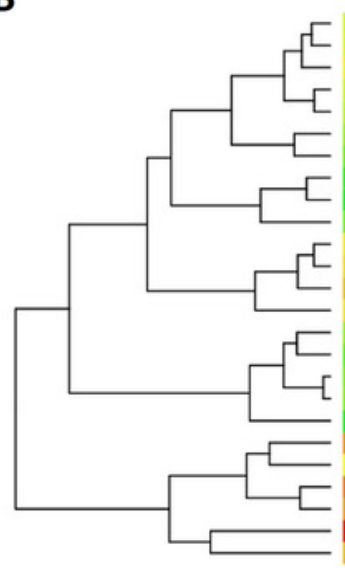

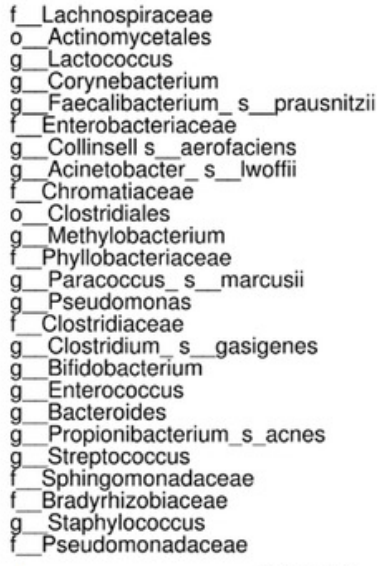

Human milk Neonatal stool

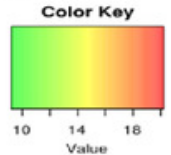




\section{Figure 6}

Probable origin of bacteria in the neonatal stool.

(A) Microbial source tracker analysis showing the proportion of bacteria identified in the neonatal stool classified by source ( $p<0.001$, Wilcoxon signed-rank test). (B) Relative abundance of most common bacterial orders found in the neonatal stool classified by Qiime source tracker analysis as "Human milk" and "unknown source".

A

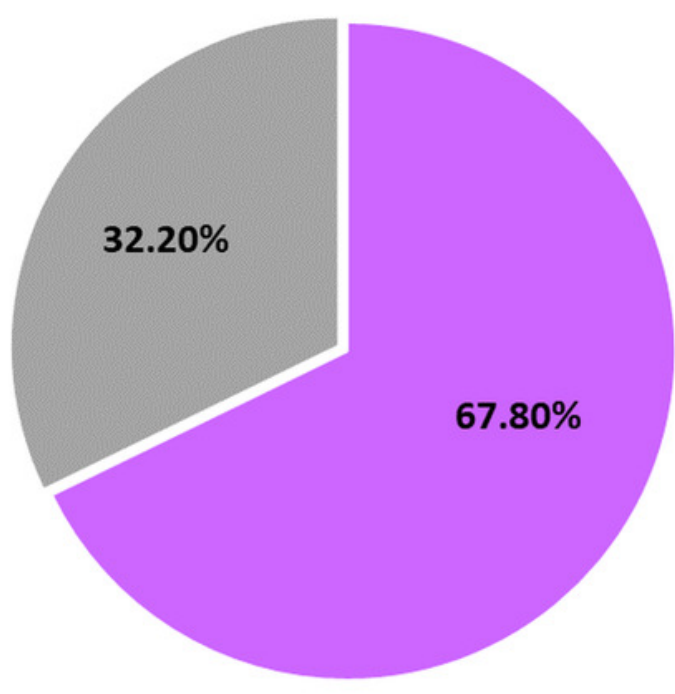

- Human Milk $\amalg$ Unknown Source
B

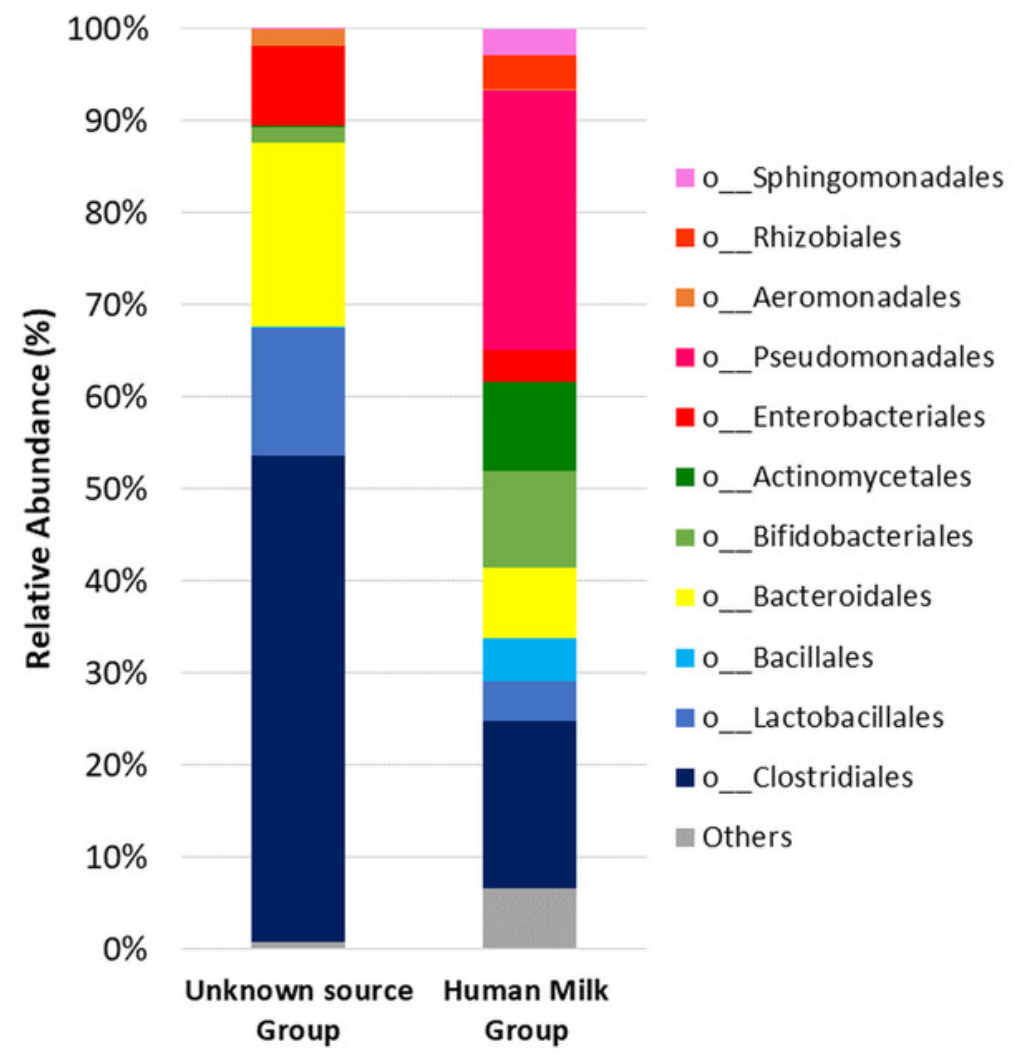




\section{Figure 7}

Prediction of functional microbial metabolic pathways using PICRUSt analysis (KEGG level three).

The figure shows the abundance of 10 statistically significant metabolic pathways between human milk (crusta color) and neonatal stool (light blue color) bacterial communities. All statistically significant pathways $(q<0.05)$ are included in Table S8.

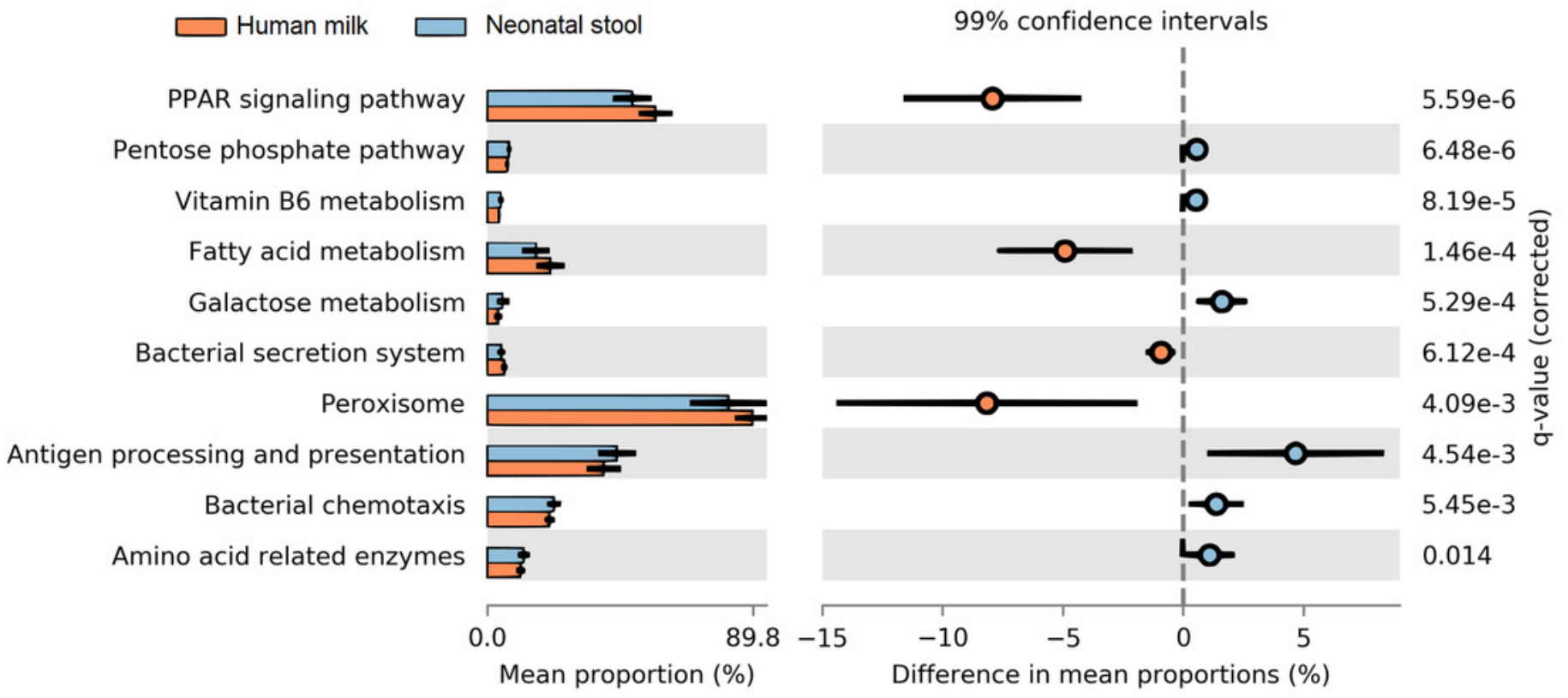




\section{Table 1 (on next page)}

Sociodemographic and clinical characteristics of the study population. 
Table 1: Sociodemographic and clinical characteristics of the study population.

\begin{tabular}{|c|c|}
\hline Maternal Data & n (\%) \\
\hline Years of age* & $22.12 \pm 5.7$ \\
\hline Birthplace & \\
\hline State-of-Mexico & $41(61.2)$ \\
\hline Mexico City & $14(20.9)$ \\
\hline Other (Oaxaca, Puebla, and Veracruz states) & $12(17.9)$ \\
\hline Main activity & \\
\hline Housewife & $60(89.6)$ \\
\hline Student & $1(1.49)$ \\
\hline General employee & $6(8.96)$ \\
\hline Educational level** & \\
\hline Elementary school & $17(25.4)$ \\
\hline High school & $21(31.3)$ \\
\hline College & $25(37.3)$ \\
\hline None & $4(5.97)$ \\
\hline Parity & \\
\hline Uniparous & $27(40.3)$ \\
\hline Multiparous & $40(59.7)$ \\
\hline Neonate's delivery mode & \\
\hline Vaginal & $46(68.7)$ \\
\hline C-Section & $21(31.3)$ \\
\hline Neonatal data & n (\%) \\
\hline $\begin{array}{l}\text { Age at sample collection, days*** } \\
<3 \\
4-6\end{array}$ & $\begin{array}{c}61(91.0) \\
6(9.0)\end{array}$ \\
\hline Sex & \\
\hline Female & $40(59.7)$ \\
\hline Vaginal & $28(41.8)$ \\
\hline C-section & $12(17.9)$ \\
\hline Male & $27(40.3)$ \\
\hline Vaginal & $18(26.9)$ \\
\hline C-section & $9(13.4)$ \\
\hline
\end{tabular}

*Expressed as mean \pm standard deviation, $\mathrm{n}-$ sample number, State-of-Mexico $\left(19.6049^{\circ} \mathrm{N} 99.0606^{\circ} \mathrm{O}\right)$, Mexico City $\left(19.4285^{\circ} \mathrm{N}\right.$ $\left.99.1277^{\circ} \mathrm{O}\right)$, Other states: Oaxaca $\left(17.0654^{\circ} \mathrm{N} 96.7236^{\circ} \mathrm{O}\right)$, Puebla $\left(19.0379^{\circ} \mathrm{N} 98.2035^{\circ} \mathrm{O}\right)$, Veracruz $\left(19.181^{\circ} \mathrm{N} 96.1429^{\circ} \mathrm{O}\right) . *^{*}$ Equivalent based on U.S. Department of Education (McFarland et. al., 2018). ***Postpartum days. 
Table 2 (on next page)

Selected studies of paired human milk-infant gut microbiota profiles in different populations. 
Table 2: Selected studies of paired human milk-infant gut microbiota profiles in different populations.

\begin{tabular}{|c|c|c|c|c|c|c|c|}
\hline Population & TS & $\mathbf{n}$ & D & Method & Predominant taxon human milk & Predominant taxon infant stool & Reference \\
\hline Mexican & $\mathrm{CS}$ & 67 & $0-6$ & $\begin{array}{l}\text { Ion Torrent / } \\
\text { (V3) }\end{array}$ & $\begin{array}{l}\text { Staphylococcus, Kaistobacter, } \\
\text { Paracoccus, Pseudomonas. }\end{array}$ & $\begin{array}{l}\text { Pseudomonadaceae, Bifidobacterium, } \\
\text { Clostridium, Bacteroides. }\end{array}$ & $\begin{array}{l}\text { This } \\
\text { study }\end{array}$ \\
\hline $\begin{array}{l}\text { Hispanic- } \\
\text { Latino- } \\
\text { White }\end{array}$ & LG & 90 & $1-7$ & $\begin{array}{l}\text { Illumina / (V3- } \\
\text { V4) }\end{array}$ & $\begin{array}{l}\text { Moraxellaceae, Staphylococcaceae, } \\
\text { Streptococcaceae, Pseudomonadaceae }\end{array}$ & $\begin{array}{l}\text { Bifidobacteriaceae, } \\
\text { Enterobacteriaceae. }\end{array}$ & $\begin{array}{l}\text { (Pannaraj } \\
\text { et al., } \\
\text { 2017) }\end{array}$ \\
\hline Peruvian & $\mathrm{CS}$ & 42 & $30-90$ & $\begin{array}{l}\text { Illumina / (V1- } \\
\text { V3) }\end{array}$ & Streptococcus, Staphylococcus, Rothia. & $\begin{array}{l}\text { Escherichia/Shigella, Streptococcus, } \\
\text { Veillonella, Enterococcus }\end{array}$ & $\begin{array}{l}\text { (Lackey } \\
\text { et al., } \\
\text { 2019) }\end{array}$ \\
\hline Spanish & $\mathrm{CS}$ & 20 & $7-90$ & qPCR, culture & $\begin{array}{l}\text { Staphylococcus, Bifidobacterium, } \\
\text { Lactobacillus. }\end{array}$ & $\begin{array}{l}\text { S. epidermidis, Bifidobacterium } \\
\text { brevis, B. longum, Lactobacillus } \\
\text { casei, L. gasseri, L. gastricum, L. } \\
\text { salivaris. }\end{array}$ & $\begin{array}{l}\text { (Martín et } \\
\text { al., } \\
\text { 2012a) }\end{array}$ \\
\hline Spanish & $\mathrm{CS}$ & 23 & $7,14,35$ & qPCR, culture & $\begin{array}{l}\text { Staphylococcus epidermidis, S. aureus, } \\
\text { Staphylococcus spp., Enterococcus } \\
\text { faecalis, E. faecium, Streptococcus. }\end{array}$ & $\begin{array}{l}\text { Staphylococcus epidermidis, } S . \\
\text { aureus, others Staphylococcus, } \\
\text { Enterococcus, Streptococcus }\end{array}$ & $\begin{array}{l}\text { (Jiménez } \\
\text { et al., } \\
\text { 2008) }\end{array}$ \\
\hline Irish & LG & 10 & $7-14$ & $\begin{array}{l}\text { Illumina / (V3- } \\
\text { V4) }\end{array}$ & $\begin{array}{l}\text { Pseudomonas, Staphylococcus, } \\
\text { Streptococcus, Elizabethkingia. }\end{array}$ & $\begin{array}{l}\text { Bifidobacterium, Gardnerella sp., } \\
\text { Bacteroidetes. }\end{array}$ & $\begin{array}{l}\text { (Murphy } \\
\text { et al., } \\
2017 \text { ) }\end{array}$ \\
\hline Swiss & $\mathrm{CS}$ & 21 & $3-6,9-17$ & Pyrosequencing & $\begin{array}{l}\text { Pseudomonas, Ralstonia, Streptococcus, } \\
\text { Staphylococcus. }\end{array}$ & $\begin{array}{l}\text { Bifidobacterium, Bacteroidetes, } \\
\text { Parabacteroidetes }\end{array}$ & $\begin{array}{l}\text { (Jost et } \\
\text { al., 2014) }\end{array}$ \\
\hline Italian & $\mathrm{CS}$ & 8 & 90 & $\begin{array}{l}\text { Illumina / } \\
\text { Metagenome }\end{array}$ & $\begin{array}{l}\text { Corynebacterium, Kroppenstedtii, } \\
\text { Staphylococcus epidermidis. }\end{array}$ & $\begin{array}{l}\text { E. coli, Bifidobacterium, Veillonella, } \\
\text { Bacteroides. }\end{array}$ & $\begin{array}{l}\text { (Asnicar } \\
\text { et al., } \\
2017 \text { ) }\end{array}$ \\
\hline Italian & $\mathrm{CS}$ & 36 & $\begin{array}{l}2-3 \\
(\text { milk) } \\
20 \text { (stool) }\end{array}$ & $\begin{array}{l}\text { Illumina / (V3- } \\
\text { V4) }\end{array}$ & $\begin{array}{l}\text { Streptococcaceae, Paenibacillaceae, } \\
\text { Lachnospiraceae, Bifidobacteriaceae. }\end{array}$ & $\begin{array}{l}\text { Bifidobacterium, Enterobacteriaceae, } \\
\text { Streptococcaceae, Bacteroidaceae. }\end{array}$ & $\begin{array}{l}\text { (Biagi et } \\
\text { al., 2017) }\end{array}$ \\
\hline $\begin{array}{l}\text { African } \\
\text { (Kenya, } \\
\text { Ethiopia }\end{array}$ & $\mathrm{CS}$ & 377 & $30-90$ & $\begin{array}{l}\text { Illumina / (V1- } \\
\text { V3) }\end{array}$ & Corynebacterium, Streptococcus. & Veillonella, Lactobacillus. & $\begin{array}{l}\text { (Lackey } \\
\text { et al., } \\
2019)\end{array}$ \\
\hline
\end{tabular}

Abbreviations: n, number of samples; TS, type of study; CS, Cross sectional study; LG, longitudinal study; D, days after delivery where samples were taken; Method, method of analysis of 16S rRNA gene. 


\section{Table 3 (on next page)}

Reports of function of most abundant taxa found in this study in both, human milk and neonatal stool. 
Table 3: Reports of function of most abundant taxa found in this study in both, human milk and neonatal stool.

Taxa

(1)

\section{Immune function}

Associated with growth inhibition and spread of $S$. aureus.

Propionibacterium mitigates intestinal inflammation via Th17 cell regulation and maintenance of T-cells and IL-10 in infants fed with breast milk.

Protective factor against the development of necrotizing enterocolitis in preterm infants.

Modulation and maintenance of the immune response.

Potent stimulator of NK cells and cytokine release through its glycosphingolipids.

Promotes the protection against chemically induced colitis through the development of FOXP3 $+\mathrm{T}$ Reg cells in mice.

\section{Clostridiaceae}

Protection against IgE-mediated disease.

Promotes the generation of Th17 cells in mice by stimulating IL- 6 and IL-23.

Development of the neonatal immune system.

Staphylococcus

Super antigen function stimulates the systemic secretion of $\operatorname{IgA}$ in neonates, protecting against allergies.

The pili and extracellular polysaccharides promote the modulation of the infant immune system without causing an adverse inflammatory response.

Bifidobacterium Induction of T-reg cells via butyric acid and propionic acid in mouse models and cell lines.

Decrease the incidence of allergies.

\section{Reference}

(Shu et al., 2013)

Colonization and metabolism

Involved in early gut colonization in

(Colliou et al.,

2017; Morrow et Prepares the gut environment for late al., 2013) colonizers such as Faecalibacterium and Coprococcus, which depend on the

(Colliou et al., presence of SCFA. 2017)

(D'Auria et al., Colonizer of the breast ductal system and 2013)

mammary tissue.

(Chan et al., 2016)

(Long et al.,2007) Ability to degrade aromatic hydrocarbons mainly associated with breast cancer.

(Urbaniak et al., 2014)

(Atarashi et al., Associated with carbohydrate metabolism 2011) by pentose metabolism.

(Cynkin \& Delwiche., 1958)

(Kamada et al.,

2013; Morrison \&

Preston., 2016)

Butyrate producer.

(Morrison \& Preston., 2016)$$
\text { 2011) }
$$

(Lundell et al., 2009)

First colonizer of the gut tract in the first month by overexpression of adhesionrelated genes.

(Martín et al., Ability to degrade high concentration of (Duncan et al., 2002; Urbaniak et 2012a) oligosaccharides in human milk. al., 2016)

Exceptional capacity to participate in the saccharolytic fermentation of carbohydrates, which end-products that positively affect host cells and gut bacterial community.

(Bottacini et al., Early gut colonizer, with high capacity to 2017) persist and to colonize

(Turroni et al., 2014) 